This item is the archived peer-reviewed author-version of:

\title{
Reference:
}

McHenry M. J., Anderson P. S. L., Van Wassenbergh Sam, Matthews D. G., Summers A. P., Patek S. N..- The comparative hydrodynamics of rapid rotation by predatory appendages

The journal of experimental biology - ISSN 0022-0949 - 219:21(2016), p. 3399-3411

Full text (Publisher's DOI): http://dx.doi.org/doi:10.1242/JEB.140590

To cite this reference: http://hdl.handle.net/10067/1364260151162165141 


\section{The comparative hydrodynamics of rapid rotation by predatory appendages}

M. J. McHenry ${ }^{1}$, P. S. L. Anderson ${ }^{2 x^{*}}$, S. Van Wassenbergh ${ }^{3,4^{*}}$, D. G. Matthews ${ }^{5}$, A. Summers ${ }^{6}$, S. N. Patek ${ }^{+2}$

* equal authorship between these authors

${ }^{1}$ Department of Ecology \& Evolutionary Biology, 321 Steinhaus Hall, University of California, Irvine, CA 92697-2525, U.S.A.

${ }^{2}$ Department of Biology, Duke University, Durham, NC, 27708 U.S.A.

${ }^{3}$ Department of Biology, Universiteit Antwerpen, Universiteitsplein 1, 2610 Antwerpen, Belgium

${ }^{4}$ Département d'Ecologie et de Gestion de la Biodiversité, UMR 7179 C.N.R.S/M.N.H.N., 57 rue Cuvier, Case Postale 55, 75231 Paris Cedex 05, France

${ }^{5}$ Department of Biology, University of Massachusetts Amherst, Amherst, MA 01002 U.S.A.

${ }^{6}$ Friday Harbor Laboratories, University of Washington, 620 University Rd., Friday Harbor, WA 98250

+Corresponding author:

S. N. Patek

Department of Biology

Duke University

Durham, NC 27708 U.S.A.

${ }^{x}$ Current address:

Department of Animal Biology University of Illinois, Urbana-Champaign Urbana, IL 61801

Running Title: Fast rotating appendages

Key words: drag, feeding, kinematics, torque, scaling, phylogenetic comparative methods 


\section{Abstract}

Countless aquatic animals rotate appendages through the water, yet fluid forces are typically modeled with translational motion. To elucidate the hydrodynamics of rotation, we analyzed the raptorial appendages of mantis shrimp (Stomatopoda) using a combination of flume experiments, mathematical modeling, and phylogenetic comparative analyses. We found that computationally-efficient blade-element models offered an accurate first-order approximation of drag, when compared with a more elaborate computational fluid-dynamic model. Taking advantage of this efficiency, we compared the hydrodynamics of the raptorial appendage in different species, including a newly-measured spearing species, Coronis scolopendra. The ultrafast appendages of a smasher species (Odontodactylus scyllarus) were an order-ofmagnitude smaller, yet experienced similar drag-induced torque as a spearing species (Lysiosquillina maculata). The dactyl, a stabbing segment that can be opened at the distal end of the appendage, generated substantial additional drag in the smasher, but not in the spearer that uses the segment to capture evasive prey. Phylogenetic comparative analyses revealed that larger mantis shrimp species strike more slowly, regardless of whether they smash or spear their prey. In sum, drag was minimally affected by shape, whereas size, speed and dactyl orientation dominated and differentiated the hydrodynamic forces across species and sizes. This study demonstrates the utility of simple mathematical modeling for comparative analyses and illustrates the multi-faceted consequences of drag during the evolutionary diversification of rotating appendages.

\section{Summary Statement}

Rapidly rotating appendages are approximated effectively by blade element analysis when compared to computational fluid dynamics. Comparative analyses of mantis shrimp strikes 
reveal that their hydrodynamics are minimally affected by shape and strongly impacted by size, kinematics and, to a lesser extent, the orientation of the stabbing dactyl.

\section{Introduction}

The diverse array of aquatic animals that rotate their appendages for locomotion and prey capture offers rich material for considering the role of hydrodynamics in morphological and kinematic diversification (Fish 1984; Johansson and Lauder 2004; Koehl 1996; McHenry, et al. 2003; Ngo and McHenry 2014; Richards 2010; Webb and Blake 1985). While the drag forces in terrestrial systems are often negligible, the aquatic appendages of dragonfly larvae, snapping shrimp, and mantis shrimp, for example, necessarily incur substantial drag (Anker, et al. 2006; McHenry, et al. 2012; Tanaka and Hisada 1980; Versluis, et al. 2000). Therefore, relationships among the parameters that influence drag have the potential to inform interpretations of morphological diversity.

Shape, size and velocity influence how drag resists the motion of a body moving through water. Drag is generated by shear stress and pressure differences that the fluid generates along the body's surface. When the body is translated through the water, drag is commonly modeled with the following equation:

$$
=\frac{1}{2} \quad 2
$$

where $\rho$ is the density of the fluid medium, $S$ is a characteristic surface area on the object moving through the fluid, $v$ is the linear velocity of the object relative to the fluid and $C_{d}$ is the drag coefficient, a non-dimensional measure of shape. The drag coefficient is typically determined from drag measured by a force transducer for a body exposed to the uniform flow generated by a flume (e.g., Van Wassenbergh, et al. 2015b). In contrast, a rotating body is exposed to flow that varies linearly along its length. A blade-element model of drag may 
account for this position-dependency as the sum of elements along the appendage's length (Blake 1979). For each instant in the rotation of an appendage, this sum may be formulated from measurements of the dimensions of each element, probable values for its drag coefficient, and its position-dependent velocity (McHenry et al., 2003). This approach treats all elements as independent force-generating units and thereby neglects factors like span-wise flow and the high shear stress that may be generated at the distal end (e.g., Dickinson, et al. 1999; Lentink, et al. 2009). The relative simplicity of the blade-element approach yields a method for calculating drag that is computationally-efficient and therefore amenable to comparative analysis (Richards 2010; Walker 2004). However, it is unclear if the simplifying assumptions of a blade-element approach are violated for any particular rotating appendage. Therefore, the present study compared the predictions by blade-element modeling against both experimental approaches and more elaborate computational analyses.

To fully incorporate the effects of rotation on hydrodynamics, many studies have employed computational fluid dynamics (CFD) (e.g., Jiang and Kiørboe 2011; Li, et al. 2012; Liu, et al. 1996; Van Wassenbergh, et al. 2015a). CFD analyses can consider the fluid forces generated by complex geometries with fully-resolved volumetric flow fields. However, the investment in the development and computational resources to perform CFD simulations are sufficiently intensive that they typically preclude large-scale comparative, evolutionary analyses that incorporate detailed morphological variation. An analysis of rapidly-rotating pipefish snouts found that CFD models agreed with the predictions of a more simple bladeelement model, where drag was treated as the sum of independent structural elements with linear flow assumed (Van Wassenbergh and Aerts 2008). Similarly, an analysis of a hovering fruit fly also yielded convergent results between blade element and CFD models (Walker 2002). In contrast, in the context of the more complex aerodynamics of flapping 
flight, a modified CFD analysis performed better than a blade element approach (Nakata, et al. 2015).

Mantis shrimp (Stomatopoda) offer an intriguing system in which to examine the effects of shape, size and velocity on drag forces (Fig. 1). "Smasher" mantis shrimp evolved from "spearers" (Porter, et al. 2010) and, during this transition, the dactyl-open evasive prey capture motion characteristic of spearers, switched to a primarily closed-dactyl, hammering motion directed at hard-shelled prey (Patek 2015). Along with this shift in the orientation and target of the raptorial strike, smashers dramatically increased in speeds and accelerations (Table 1) (Cox, et al. 2014; deVries, et al. 2012; Kagaya and Patek 2016), evolved enhanced elastic energy storage capabilities (Patek, et al. 2013; Rosario and Patek 2015), yet also experienced a substantial decrease in range of body size and appendage size compared to their ancestral spearers (Anderson, et al. 2014; Blanco and Patek 2014). Thus, the evolutionary shift to smashing encapsulates the major axes of drag: shape, speed and size.

The goal of the present study was to analyze the hydrodynamic consequences of kinematic and morphological variation in the fast rotational motion of the mantis shrimp raptorial appendage. We evaluated the methods of drag measurement, blade element modeling and CFD to quantify drag on this rapidly rotating structure. In addition, we performed a new kinematic analysis of a spearing mantis shrimp, Coronis scolopendra, and conducted phylogenetic comparative analyses of the relationships among drag-related parameters across mantis shrimp. We considered the torque generated by drag (hence-forth referred to as "drag-torque") and the propensity of an appendage to generate this torque, which was measured with the drag-torque index (McHenry et al., 2012). These approaches allowed us to address three guiding questions: (1) How does the balance of evolutionary variation in kinematics, shape and size influence variation in drag across stomatopods? Given the wide range of high Reynolds numbers for this system (Table 1), can we make 
simplifying assumptions about drag calculations, in the context of the added complexities of rotational, rather than translational, motion? (3) Given the results of the comparative analyses and fluid dynamic methodological comparisons, which aspects of mantis shrimp fluid dynamics are most relevant to evolutionary diversification and should be the primary focus of future fluid dynamic analyses in mantis shrimp?

\section{Methods}

\section{Strike kinematics of Coronis scolopendra}

We supplemented previously-published kinematics of very small and larger spearers through high speed videos of a medium-sized spearer, Coronis scolopendra (Crustacea: Stomatopoda: Lysiosquilloidea: Nannosquillidae). C. scolopendra individuals were collected in Florida (License \#SAL-13-1278-SRP) and shipped to the University of Massachusetts Amherst for experiments. After arrival, they were kept in recirculating aquarium systems $\left(24-28^{\circ} \mathrm{C}, 34-36\right.$ ppt salinity), where the animals formed their own burrows in the provided substrate (sugarsized Oolite, Aragonite, CaribSea, White City, FL, USA).

C. scolopendra strikes were elicited by presenting a live brine shrimp either by pipette or forceps. Strikes were filmed using a digital high-speed imaging system (10,000-15,000 fps, 1/10,000 - 1/15,000 shutter speed, 512x512-512x256 pixels, APX-RS, Photron Inc., San Diego, CA, USA) and illuminated with halogen and fiber optic lights. A ruler was placed in the plane of the striking animal to calibrate each series of videos.

Five points were tracked manually in each image sequence of a raptorial appendage strike (Suppl. Fig. 1). Tracking began when the carpus rotation started, and ended when the appendage made contact with the prey or feeding device (custom software by the authors, v. R2011a, The Mathworks, Natick, MA, USA). We analyzed only videos for which the appendage was in focus and remained in-frame throughout the strike. The five points 
included a central point on the merus as well as points on the distal ends of the merus, carpus, propodus, and dactyl (Suppl. Fig. 1). Prey distance was measured as the distance between the center of the mantis shrimp's eye and the closest part of the prey to the mantis shrimp. Digitizing error was quantified by repeating the position measurement of the propodus for each video segment ten times. We picked a strike with kinematics close to the overall mean and digitized 20 frames shortly after the beginning of the propodus rotation. We found the percent error in each measured displacement to be $9.2 \pm 3.5 \%$ (range $3.5-16.5 \%$ ).

The kinematics of the raptorial appendage were calculated from the coordinate measurements. The angular displacement of the propodus in radians was calculated by dividing the linear displacement of its distal tip by the propodus length. We found the rates of angular change in this motion from the first and second derivatives of a least-squares fit of a tenth-order polynomial determined to positional data, as done previously (Cox, et al. 2014; deVries, et al. 2012). These calculations, and all other kinematic analyses were performed in Matlab (v. R2013b, The Mathworks, Natick, MA, USA). If the maximum speed occurred at the beginning or end of the digitized portion of the strike, then the strike was eliminated from the dataset, because the true peak speed could have occurred outside the digitized segment of the strike. Maximum linear and angular speed and acceleration were determined for each strike. These values were averaged across all strikes from the same animal and are reported for each animal \pm 1 standard deviation.

Using linear models, we tested whether kinematics were correlated with body size using propodus length as a proxy for body size ('R v. 3.0.2, R_Core_Team 2014). Propodus length is an effective proxy for body size (Claverie, et al. 2011; deVries, et al. 2012; Patek and Caldwell 2005). 


\section{Strike kinematics across species}

We used previously-published measurements of strike kinematics in addition to our present measurements of $C$. scolopendra to determine the scaling of our physical models and to provide the basis for a sensitivity analysis on the effects of strike kinematics (Fig. 2). We incorporated kinematics from Lysiosquillina maculata and Alachosquilla vicina (deVries, et al. 2012), Gonodactylus smithii (Cox, et al. 2014; Patek, et al. 2007) and Neogonodactylus bredini (Kagaya and Patek 2016). Using the original data from these published studies, we re-analyzed the descriptive statistics so that analyses were consistent across studies. We measured the propodus length (length of the propodus between the propodus-dactyl joint to the proximal-most point visible on the propodus) and the striking body length (length from the propodus-dactyl joint to the insertion point of the lateral extensor muscle on the dorsal surface of the carpus) for all of the individuals in this and previous studies using archived digital images (Fig. 2).

We performed phylogenetic least squares regression (PGLS) on logged species averages against logged average striking body length in order to examine the relationship between size and kinematics across species. This analysis considered the maximum observed values for each individual to calculate the average maximum values per species for speed, linear acceleration, angular velocity and angular acceleration. We incorporated a pruned and time-calibrated molecular phylogenetic tree based on nucleotide sequence data (Porter, et al. 2010) with hard-bound calibration points from fossil data to establish time calibrations (Claverie and Patek 2013). PGLS analyses were performed in the R package caper (Orme, et al. 2012) with delta and kappa fixed at 1 and lambda estimated using maximum likelihood methods, which allows the model to deviate from a strict Brownian motion.

We compared three species to explore the effects of strike kinematics on fluid forces. G. smithii was employed as a representative smasher, L. maculata represented large spearers, 
and A. vicina served as a characteristic small spearer (Fig. 2). We applied a sensitivity analysis that examined the effects of kinematics on the maximum torque and energetic expense generated by drag (described below). To this end, we sought to reduce the number of parameters required to approximate the differences in strike kinematics among species. The striking motion, defined as the angle of the propodus-dactyl unit during a strike with respect to time, approximated a sigmoidal curve for all species. The species primarily differed in terms of strike duration and angular excursion of the appendage. Upon further inspection, we found that the excursion, $\gamma_{\mathrm{d}}$ (in radians), was correlated with the strike duration (in seconds), $T$, as specified by the following equation:

$$
\gamma_{\mathrm{d}}=35.7 T+1.1 \text {. }
$$

Therefore, much of the variation in strike kinematics across species may be explained by differences in strike duration.

We approximated the strike kinematics of each species by using one average strike from L. maculata that exhibited the characteristic sigmoidal pattern that we found in all species (Suppl. Fig. 2). After normalizing for the strike duration and maximum excursion, we used a non-linear least-squares fit to characterize this strike with the following fifth-order polynomial:

$$
\bar{\gamma}=-1.45 \bar{t}^{5}+0.72 \bar{t}^{4}+3.48 \bar{t}^{3}-2.89 \bar{t}^{2}+1.13 \bar{t},
$$

where $\bar{\gamma}$ and $\bar{t}$ were the respective values of normalized angular position (in radians) and time (in seconds). This pattern was used to vary the kinematics across species by multiplying normalized time values by the strike duration and the normalized angular position by the corresponding angular excursion (using Eqn. 2). This approach allowed us to approximate the strike kinematics across species by varying only strike duration. This approximation was tested by comparing the strike performance for kinematics of Eqn. 3 against the measured kinematics of equal duration, with all other parameters being equal. These predictions did not 
conform to a normal distribution and thus a Kolmogorov-Smirnov goodness-of-fit test was used to identify significant deviation between these two sets of predictions. We could not reject the null hypothesis for the strikes in $G$. smithii (drag energy: $P=0.64$, max torque: $P=$ 0.47, $N=47), C$. scolopendra (drag energy: $P=0.36$, max torque: $P=0.68, N=50$ ), or $L$. maculata (drag energy: $P=0.16$, max torque: $P=0.08, N=58$ ), which suggests that Eqn. 3 provides a reasonable approximation of strike kinematics. Calculations of the mean-squared error (MSE) for the fit of Eqn. 3 for each species (G. smithii MSE $=0.039 \mathrm{rad}^{2}, C$.

scolopendra $\mathrm{MSE}=0.005 \mathrm{rad}^{2}$, and L. maculata $\left.\mathrm{MSE}=0.262 \mathrm{rad}^{2}\right)$ indicated the best fit for G. smithii, which is the fastest species. The spearer, L. maculata, offered a contrast due to its high variability in strike kinematics.

\section{Drag measurements on physical models}

Our experimental consideration of the fluid dynamics of the raptorial appendage was based on drag measurements from physical models. These models were created with 3D prints that were dynamically scaled to approximate the Reynolds numbers achieved by the kinematics that we measured for mantis shrimp (Fig. 2; Suppl. Table 1). The Reynolds number is given by the following equation:

$$
\operatorname{Re}=
$$

where $U$ is the velocity of flow, $L$ is a characteristic length, and $\rho$ and $\mu$ are respectively the density and dynamic viscosity of water. The characteristic length is commonly selected as a dimension in the direction of flow, whereas we used the propodus length, which is perpendicular to flow in a strike. We used this length, because the irregularity of the crosssectional shape in the direction of flow challenged our ability to standardize a chord length across specimens. 
Dynamic scaling was achieved by constructing 3D-printed appendages at a larger size than the actual size of the appendage. This relatively large size compensated for the slow flow speeds that could be generated by the flume (detailed below) and the differences between the physical properties of the salt water $\left(\rho_{\mathrm{s}}=1025 \mathrm{~kg} \mathrm{~m}^{-3}, \mu_{\mathrm{s}}=1.08 \times 10^{-3} \mathrm{~Pa} \mathrm{~s}\right)$ encountered by a mantis shrimp and the fresh water $\left(\rho_{\mathrm{f}}=1000 \mathrm{~kg} / \mathrm{m}^{3}, \mu_{\mathrm{f}}=1.02 \times 10^{-3} \mathrm{~Pa} \mathrm{~s}\right)$ of the flume. For three of the taxa (L. maculata, G. smithii and C. scolopendra), dynamic scaling was based on speed estimated from kinematic data (Table 1). For the other two taxa, there were no published kinematic data, so the scaling was based on speed from similar taxa. G. falcatus models were run at speeds from G. smithii kinematics and H. californiensis models used speed from L. maculata. For the three relatively slow species (H. californiensis: undifferentiated; L. maculata and C. scolopendra: spearers), we were able to match and exceed the Re of measured strikes (Suppl. Table 1). We used the smaller end of the size range for the smashers G. smithii and G. falcatus in order to correctly match their Re while accommodating the size limits of the 3D printer (Z-Corp 310, 3-D Systems, USA) and the top speed of the flume ( $1 \mathrm{~m} / \mathrm{s}$, model 2436, Rolling Hills Research, El Segundo, CA, USA) (Suppl. Table 1).

The 3-D printed models were based on scans of the dactyl and propodus segments acquired from micro-computed tomography (micro-CT, Model HMXST225, X-Tek, Nikon Metrology NV, Leuven, Belgium). The carpus, which is proximal to the propodus, was excluded due to its modest contribution to the generation of drag (McHenry, et al. 2012). The scans were performed for two smasher species (Gonodactylus smithii and Gonodactylaceus falcatus), two spearer species (Coronis scolopendra and Lysiosquillina maculata) and an undifferentiated species (Hemisquilla californiensis) (Figs. 1,2). The individual dactyl and propodus segments were digitally separated (Mimics v13.0 for X64, Materialize, Belgium) and their wetted surfaces were identified and smoothed (Geomagic Studio 11, 64-bit edition, 
Geomagic Inc., NC, USA). The resulting geometries were printed and then hardened with cyanoacrylate to create enlarged physical models of the dactyl and propodus that could be mounted with the dactyl in either an opened or closed position relative to the propodus (Fig. $1)$.

We measured the drag force exerted on the physical models over a range of flow speeds generated by the flume. Each physical model was suspended in the working section of the flume with the long-axis of the propodus oriented perpendicularly to the flow velocity (Fig. 3). The models were suspended in center of the flume's working area with a sting to which the model was magnetically-attached close to the model's center of mass. The center of mass was determined as the balance point of the model when suspended by a string. The sting was positioned such that force was applied in the direction of flow velocity (Fig. 3) against a force sensor (DS2-4, Imada Inc,. IL, USA). Drag was measured with the dactyl opened into the oncoming flow. Force measurements were recorded for $60 \mathrm{~s}$ at $4 \mathrm{~Hz}$ with logging software (SW-1 Data Acquisition package, Imada Inc., IL, USA). A baseline recording was performed prior to each experiment (11 flow speeds) to determine the drag on the sting without the model attached, which we subtracted from the measured force. Force measurements were divided by the mechanical advantage of the sting (Fig. 3).

\section{Computational fluid dynamics}

We tested a blade-element model of the hydrodynamics of a rotating structure with computational fluid dynamics (CFD). We animated the CFD model with the strike kinematics of the smasher, G. smithii, and then we approximated its geometry with a series of 19 frustum segments (virtual slices of the appendage) connecting 20 ellipses that match the crosssectional shape along the length of the appendage (Suppl. Fig. 3). This multi-frustum model was created in the CAD program GAMBIT v. 2.4.6 (Ansys Inc., Canonsburg, USA) and then 
imported into ANSYS DesignModeler 14.5.7 where it was surrounded by a spherical flow domain with a radius of $0.05 \mathrm{~m}$. The flow domain was meshed with 11 million tetrahedral which increased in size gradually away from the multi-frustum model (growth rate 1.1 starting from a mesh element size of $20 \mu \mathrm{m}$ ) using ANSYS Meshing 14.5.7. This density was appropriate, because a mesh convergence test showed that the hydrodynamic torque at the end of the simulation differed by only $1.5 \%$ from a considerably coarser mesh (3.5 million elements; mesh element size of $40 \mu \mathrm{m})$. The multi-frustum model was subjected to a constant acceleration of $4 \times 10^{6} \mathrm{rad} \mathrm{s}^{-2}$, from a speed of zero $\mathrm{rad} \mathrm{s}^{-1}$ at time $=0$ to a speed of $2800 \mathrm{rad}$ $\mathrm{s}^{-1}$ at time $=0.70 \mathrm{~ms}$. This corresponds closely to the mean peak velocity $\left(2821 \mathrm{rad} \mathrm{s}^{-1}\right)$ and the time to this peak velocity $(0.72 \mathrm{~ms})$ for G. smithii (Table 1). Simulations solved the flow field for the full Navier-Stokes equations for unsteady laminar flow (ANSYS Fluent 14.5.7.) with a fixed time-step having a $3.5 \mu$ s interval. Quartering the time step size had a negligible effect on the calculated torque ( $<0.7 \%$ difference). In these simulations, the mesh of the entire flow domain was rotated at constant acceleration with respect to the fixed reference frame (DEFINE-ZONE-MOTION function in Fluent). The outer boundary of the spherical flow domain was defined as a pressure outlet with zero gauge pressure and backflow perpendicular to the boundary surface, and the surface of the multi-frustum model was defined with a no-slip boundary condition.

To assist in validating the rotational blade-element models, a second type of CFD simulation was performed with the multi-frustum model of the appendage in a steady, linear flow of $20 \mathrm{~m} \mathrm{~s}^{-1}$. To do so, the multi-frustum model was placed inside a cylindrical flow domain with a length of $0.3 \mathrm{~m}$ and a radius of $0.05 \mathrm{~m}$. It was positioned on the central axis of the cylinder at $0.06 \mathrm{~m}$ from the cylinder's top plane. It was oriented so that flow from the cylinder's top plane (defined as a flow-velocity inlet) to the base plane (defined as a pressure outlet) first impacts the leading edge of the striking appendage, and so that its long axis is 
perpendicular to the incoming flow. The side plane of the cylinder was defined as a wall with a slip-velocity of $20 \mathrm{~m} \mathrm{~s}^{-1}$, so that it moves at the same speed and direction as the flow. The stationary surface of the multi-frustum model was defined with a no-slip boundary condition. To better resolve the complex flow patterns in a fully developed wake, we used Menter's Shear Stress Transport model in ANSYS Fluent (Menter 1994). Previous studies showed that this model accurately calculates the steady-state drag force of reference shapes such as cubes and spheres as well as more complex biological shapes at similar $\operatorname{Re}$ (Goyens, et al. 2015; Van Wassenbergh, et al. 2015b) A mesh convergence analysis showed that the drag force on the multi-frustum model still increased significantly $(+35 \%)$ from a mesh with 3.5 to 11 million cells, but no longer when refining from 11 million to 16 million cells $(+0.1 \%)$ (Suppl. Fig. 4). We retained the latter simulation (mesh element size at the multifrustum model of $1.6 \mu \mathrm{m}$ ), which showed clear iterative convergence after 2000 iterations. The drag coefficients of each individual frustum segment, as well as the overall drag force on the multi-frustum model was calculated from the flow solution.

From the unsteady CFD simulation of the rotating appendage, the torque about the joint exerted by the water on the elliptical cylinder was determined by summing the torques due to viscous and pressure forces on each surface element of the multi-frustum model. This calculation was compared with the prediction for the same conditions with a blade-element model, as done previously (Van Wassenbergh, et al. 2008). As detailed below, a bladeelement model calculates the quasi-steady fluid forces as the sum of forces generated by virtual sections along the structure. In this implementation, the mantis shrimp appendage was divided into 19 segments and the torque generated by drag and added mass were calculated for each interval of time (equations 2.6 to 2.15 in Van Wassenbergh, et al. 2008).

To evaluate the influence of the drag coefficients $\left(C_{\mathrm{d}}\right)$ on the accuracy of the bladeelement model, three versions of blade-element models were compared: (1) a model using 
$C_{\mathrm{d} S}$ from measurements of a range of long elliptical cylinders with different aspect ratios (see Eq. 5 below), (2) a model that uses the $C_{\mathrm{d} S}$ calculated for each individual frustum segment of the steady-flow CFD simulation described above, and (3) a model that uses the total drag force from the steady-flow CFD simulation to scale the literature values of long elliptical cylinders (Hoerner 1965) so that the total drag force calculated by the blade-element model for steady, linear flow equals the value from CFD. This third version of the blade-element model is similar to the one described below, as it also uses a drag force quantification of the entire shape to fine-tune the aspect-ratio dependent $C_{\mathrm{d}} s$ of the individual blade elements. To focus on the effect of drag forces, differences in added mass torque between the bladeelement models and CFD at the instant of pure added mass resistance (the first time steps of the simulation when velocity is very low and drag is negligible) were cancelled out by adding a constant torque $\left(8.5410^{-5} \mathrm{~N}\right.$ m or $19 \%$ of the CFD's added mass torque). This analysis allows us to test the case of an extreme rotational acceleration as observed in the smashing mantis shrimp.

\section{Modeling torque from drag measurements}

We modeled the torque generated by drag during the strike of a raptorial appendage from our measurements of dynamically-scaled models. This necessitated a consideration of the differences in flow between a rotating structure (as in mantis shrimp) and one exposed to the translating flow in a flume (as in our drag measurements). Our physical models were oriented perpendicularly to flow, such that they encountered the same velocity at the distal and proximal ends of the structure. This is equivalent to the flow around an appendage if it were to translate through the water with a fixed orientation. However, the dactyl rotates through the water around a point near the proximal end, so flow velocity varies linearly along its length. It follows that torque generated by drag (i.e., 'drag torque') is determined more by the 
size and shape of the appendage at its distal end than the proximal end. Here we integrate the drag measurements at different speeds into an analysis of drag torque for a rotational strike.

We modeled drag torque using a quasi-steady blade-element approach. This model treats the morphology as a series of chord-wise (i.e., in the direction of flow) elements that vary in their dimensions to conform to the shape of the dactyl/propodus unit. The total drag generated by this structure in translating flow $(D)$ was considered equal to the sum of drag on all elements, as indicated by the following equation (Batchelor 1967):

$$
=\frac{1}{2} \rho \sum_{=1}\left({ }_{\mathrm{d}}\right){ }^{2} \Delta
$$

where $\Delta l$ is the thickness (i.e., linear dimension along the longitudinal axis of the structure) and $h$ is the width (i.e., linear dimension perpendicular to flow) of each element $i$, with $n$ equaling the total number of elements. This measure of drag coefficient, $\left(C_{\mathrm{d}}\right)_{i}$, may be distinguished from the coefficient for the entire appendage, because it represents the contribution of an individual element. The drag coefficient for each element was modeled in a form similar to a uniform elliptical cylinder, given by the following equation (Hoerner 1965):

$$
{ }_{\mathrm{d}}=(1+-)+1.1(-)
$$

where $k$ is a shape coefficient that varies with the geometry of the structure and $c$ is the chord length (i.e., linear dimension in the direction of flow). This equation is valid only for reference areas of the elements projected on a plane perpendicular to the flow (Eqn. 5). We measured the dimensions ( $c$ and $h$ ) from our micro-CT scans with the dactyl/propodus unit (with the dactyl closed against the propodus) for 20 evenly-spaced elements. For a uniform elliptical cylinder, a fixed value for the shape coefficient $(k=0.015)$ is predictive of empirical drag measurements (Hoerner 1965). However, many raptorial appendages are neither 
uniform, nor elliptical in cross-section. We therefore treated $k$ as an unknown variable that we calculated from our drag measurements of each physical model.

The shape coefficient, $k$, was determined for each of our dynamically-scaled models from our measurements of drag. We scripted a program in Matlab that used nonlinear leastsquares (using the 'Isqcurvefit' function) to find the value of $k$ (Eqn. 6) that minimized the deviation of predicted drag (calculated with Eqn. 5 using our morphometric measurements of $\Delta l$ and $h$ ) from our drag measurements across flow speeds. The effect of the shape of elements along the appendage was reflected in these empirically-derived values of $k$.

This blade-element model of drag provided the basis for modeling the torque generated during a strike. The drag torque $(\tau)$ was modeled with the following equation (McHenry, et al. 2012):

$$
\tau=\frac{1}{2} \rho_{\mathrm{d}}{ }^{5}\left(\frac{\mathrm{d} \gamma}{\mathrm{d}}\right)^{2}
$$

where $\mathrm{d} \gamma / \mathrm{d} t$ is the angular velocity and $L$ is length of the dactyl/propodus unit (i.e., equal to the characteristic length for Re, Eqn. 4). The drag-torque index, $T_{\mathrm{d}}$, indicates the propensity of an appendage to generate drag torque during a strike. Its calculation incorporates the variation in $C_{\mathrm{d}}$ (Eqn 6) and associated shape coefficients $(k)$ of blade-elements that we determined from drag measurements, as articulated by the following equation (McHenry, et al. 2012):

$$
{ }_{\mathrm{d}}=\frac{1}{5} \sum_{=1}\left({ }_{\mathrm{d}}\right){ }^{3} \Delta
$$

where $r$ is the distance between an element and the pivot point of the dactyl/propodus unit, approximated as the proximal-most point on the propodus.

We calculated drag torque index, $T_{\mathrm{d}}$, across all of our measured species with the dactyl in the open and closed position. We assessed whether the magnitude of $T_{\mathrm{d}}$ variation was greater across species or across dactyl orientation. Given that this is a dimensionless 
parameter, the comparison serves as a simple heuristic for assessing the hydrodynamic effect of shape on a rotating appendage.

Finally, we compared our drag measurements and the ability of appendages to generate torque with the same analyses performed on a uniform elliptical cylinder (Fig. 2). For each appendage, we calculated the drag coefficient (Eqn. 6) of a uniform elliptical cylinder (where $k=0.015$ ) with the same mean thickness as the appendage. These coefficients of drag were used to estimate drag and drag-torque index for the elliptical cylinders. A comparison of these values with our measurements for the raptorial appendage allowed us to assess which appendages function similarly to a uniform elliptical cylinder.

\section{The effects of shape, size and kinematics on strike performance}

We used our predictions of drag torque to compare strikes across morphologies and kinematics. We evaluated the maximum value of drag torque and the energetic cost of drag $\left(E_{\text {drag }}\right)$ which was calculated by integrating drag torque over the angular displacement of a strike (McHenry, et al. 2012):

$$
E_{\text {drag }}=\int_{0}^{\gamma \mathrm{d}} \tau d \gamma
$$

where $\gamma_{\mathrm{d}}$ is the total angular excursion over a strike. This integral was solved numerically using the 'trapz' function in Matlab with the strike excursion divided into 1000 equal intervals of time.

We used our model of drag torque (Eqn. 7) to perform a sensitivity analysis that explored the effects of kinematics, size and shape on maximum drag-torque and drag energy. Each simulation independently modified strike duration, the length of an open or closed dactyl/propodus unit, and drag-torque index over a series of 100 simulated strikes. We varied each parameter of interest by 0.75 orders of magnitude above and below the mean value for the species while setting all other parameter values equal to the mean value for each species. 
For example, G. smithii exhibited a mean strike duration of $840 \mu$ s. Simulations exploring the effects of kinematics were run at durations between $149 \mu$ s and 4.72 ms while maintaining the propodus length and drag-torque index at the mean values measured for G. smithii. For each simulation, we calculated the maximum torque (Eqn. 7) and drag energy (Eqn. 9).

\section{Results}

\section{Strike kinematics}

C. scolopendra's strikes followed a sequence typical of spearer species (Table 2): (1) the dactyl opened from the propodus, (2) the propodus slid along the merus, and (3) the propodus rotated toward the prey, and (4) the dactyl and propodus made contact with the prey. The slide of the propodus prior to propodus rotation indicated that the strikes were powered by spring-loaded skeletal elements. Prey distance from the mantis shrimp's eye was on average $7.12 \mathrm{~mm}$ (range \pm 1 s.d. $=3.68-9.94 \pm 1.96 \mathrm{~mm}$ ). The distal tip of the propodus reached an average peak linear speed of $2.1 \mathrm{~m} \mathrm{~s}^{-1}\left(0.7-3.6 \pm 0.6 \mathrm{~m} \mathrm{~s}^{-1}\right)$ and average peak linear acceleration of $2600 \mathrm{~m} \mathrm{~s}^{-2}\left(300-11000 \pm 1200 \mathrm{~m} \mathrm{~s}^{-2}\right)$. Peak linear velocity was reached from 0.2 to $6.1 \mathrm{~ms}$ after the propodus began rotating, and strike duration ranged from 2.3 to 13.1 ms.

C. scolopendra size and kinematics were not correlated when analyzed in terms of propodus length and maximum linear velocity (linear regression: $R^{2}=0.07, N=6, F_{1,5}=0.377$, $P=0.57)$. A non-significant trend was present in the analysis of propodus length and maximum linear acceleration (linear regression: $R^{2}=0.57, N=6, F_{1,5}=6.74, P=0.05$ ).

The phylogenetic regression analyses (PGLS) of C. scolopendra and five previouslystudied species revealed a significant negative association between angular kinematics and striking body length (Fig. 4; Table 1) (angular velocity: $P=0.02, R^{2}=0.76$; angular acceleration: $\left.P=0.02 ; R^{2}=0.77\right)$. Linear kinematics were not significantly associated with size, 
although linear acceleration appeared to follow a non-significant negative relationship with size $\left(P=0.06, R^{2}=0.6\right)$.

\section{Computational fluid dynamics}

We performed CFD simulations to test the accuracy of a blade-element model in estimating the drag on a rotating structure at the scale of a raptorial appendage. The simulation of steady, linear flow of $20 \mathrm{~m} \mathrm{~s}^{-1}$ on the multi-frustum model of the appendage of G. smithii showed considerable span-wise flow at the leading edge directed towards the free ends (frustum segments 1 to 3 , and 17 to 19 ; numbered from proximal to distal), coupled with lower calculated drag coefficients at these outer regions compared to literature values for infinitely long elliptical cylinders (Fig. 5a). Span-wise flow at the leading edge in the proximal direction towards the mid-region of the appendage model is observed on the proximal side of the bulging part of the appendage (frustum segments 11 to 15). Drag coefficients for long elliptical cylinder from Eq. 5 for $k=0.015$ consistently overestimated the values calculated by the CFD simulation (frustum segments 10 to 12), but the difference was most prominent for the above-mentioned frustum segments where span-wise flow was observed (Fig. 5a). According to this CFD simulation, total drag force would be overestimated by $55 \%$ when using drag coefficients from long elliptical cylinders in a bladeelement model.

The simulation of accelerated rotation of the multi-frustum model revealed a zone of high positive pressure that functioned to resist rotation at the leading edge of the elliptical cylinder. This was accompanied by a zone of high negative pressure on the proximal and lateral surfaces of the multi-frustum model (Fig. 5B,C). The performance of a blade-element model (Van Wassenbergh, et al. 2008) in approximating the torque about the fixed center of rotation as calculated by CFD, depended on the $C_{\mathrm{d}}$ input treatment (Fig. 5D-F). The model 
using the $C_{\mathrm{d}} S$ of long elliptical cylinder (Eq. 5; Hoerner 1965) showed the largest difference: a steeper increase in the resistive torque with increasing angular velocity due to drag forces caused this blade-element model to overestimate the final torque (at time $0.700 \mathrm{~ms}$ ) by $54 \%$ (Fig. 5D). The difference between the two other models and the CFD solution was much smaller: the effect of drag was underestimated at the final simulation time by $4.6 \%$ in the model that used $C_{\mathrm{d} S}$ calculated by the steady-flow CFD simulation (Fig. 5E), whereas the model with the $C_{\mathrm{d} S}$ from Hoerner (1965; Eq. 5 with $k=0$ ) decreased by $24 \%$ (to conform with the total drag force calculated by steady-flow CFD) and overestimated the resistive torque by $3.4 \%$ (Fig. 5F). In contrast, local torques along the length of the appendage yielded large differences between CFD for all three versions of the blade-element model (Fig. 5G-I). Nevertheless, a blade-element model of drag informed by a quantification of the total drag force in linear flow (Fig. 5F) offers an excellent approximation of the hydrodynamic resistance encountered by a rotating structure at the scale of a raptorial appendage. Such a model provided the basis of our calculations of the drag-torque index and the maximum torque and drag energy (see below).

\section{Drag measurements}

Our drag measurements from dynamically-scaled models allowed us to consider the hydrodynamics of different appendage shapes (Suppl. Table 2). The two smasher taxa ( $G$. smithii and G. falcatus) and the undifferentiated taxon (H. californiensis) exhibited higher drag when the dactyl was in the open position, while the drag on spearer appendages $(C$. scolopendra and L. maculata) was similar whether or not the dactyl was opened or closed against the propodus (Suppl. Table 2, Figs. 2,4).

Our blade-element model succeeded in characterizing these drag measurements. The blade-element model calculated drag from measurements of the dimensions of the appendage 
(Eqn. 5) and by fitting a value for the shape factor, $k$, included in the calculation of drag coefficient (Eqn. 6). For each physical model, the blade-element model succeeded in characterizing the variation in drag with respect to flow velocity to generate a high coefficient of determination $\left(r^{2}>0.97\right.$, Fig. 6). The smasher species, G. smithii and $G$. falcatus, with a closed dactyl, exhibited similar variation in drag with speed as predicted for a uniform elliptical cylinder with the same mean dimensions. This result emerged in spite of the fact that these species exhibited shape factors ( $k \sim 0.10$, Suppl. Table 3$)$ that were more than 7-fold greater than an elliptical cylinder $(k=0.015)$. This discrepancy is explained by the substantial variation in cross-sectional shape along the length of a raptorial appendage. Conversely, the raptorial appendage of $C$. scolopendra was relatively uniform along its length (Fig. 2) and consequently was found to possess a shape factor $(k=0.0153)$ that was similar to that of an elliptical cylinder.

\section{Effects of shape, size and kinematics on costs of movement}

The drag-torque index provides a metric for the effects of the shape on the hydrodynamics of a raptorial appendage in rotation. Among the five species considered, we found that the two spearers had lower $T_{\mathrm{d}}$ than smashers and the undifferentiated $H$. californiensis. The spearers exhibited $T_{\mathrm{d}}$ values that were similar to a uniform elliptical cylinder (Suppl. Table 3 ). This was because the spearers possessed a relatively uniform cross-sectional shape along the length of the appendage (Fig. 2). In contrast, the enlarged dactyl of a smasher at the distal end of the appendage yielded a relatively large value for the drag-torque index (Eqn. 8). Opening the dactyl serves to move a portion of the appendage toward the distal end of the appendage, where drag generates a greater torque than when the dactyl is closed. As a consequence, the values of $T_{\mathrm{d}}$ in all species were greater with the dactyl opened than when it was closed. 
We tested the individual effects of strike duration, the length of the dactyl, and the drag-torque index over a series of 100 simulated strikes for three taxa (G. smithii, $L$. maculata and C. scolopendra) (Fig. 7). These simulations revealed that the maximum torque and drag energy were most sensitive to the size of the appendage and far less sensitive to strike duration and drag-torque index (Fig. 7).

\section{Discussion}

Drag generated by the strike of a mantis shrimp is dominated by size and velocity and less so by shape. Larger mantis shrimp, regardless of appendage type, move more slowly, which indicates tradeoffs between angular kinematics and size during the diversification of mantis shrimp raptorial appendages. In spite of their distinct morphologies, differences in the shapes of the smasher and spearer appendages did not greatly alter drag. Nonetheless, we found that smashers reduced drag by closing the dactyl and that spearers, even with very substantial dactyls, did not experience a large change in drag with the dactyl open.

A blade-element approach adequately approximated drag when compared to the more computationally-intensive CFD approach. However, there were anomalies between the two approaches that warrant further investigation when considering more detailed, future analyses of energetic costs of raptorial strikes. In particular, the interaction between shape and spanwise flow suggests that shape may be important for local flow specific to rotational movement. Nonetheless, the reasonable correspondence between blade element and CFD models is good news for coarse-grained future comparative analyses that are, from this point forward, more feasible than if CFD were required. 


\section{Strike kinematics}

The kinematic data from a medium-sized spearer, $C$. scolopendra, filled a key size range for the comparison of kinematics across stomatopod appendage types (Fig. 4, Table 1).

Following the broad pattern across mantis shrimp, C. scolopendra struck with slightly slower kinematics than the smaller spearer A. vicina, and more slowly than the comparably-sized smashers, G. smithii and N. bredini. C. scolopendra used their spring and latch system, as indicated by the characteristic sliding and sudden outward rotation of the propodus and dactyl (Cox, et al. 2014; deVries, et al. 2012; Kagaya and Patek 2016; Patek, et al. 2004; Patek, et al. 2007). Across species, angular kinematics decreased with increasing appendage size. Smashers exhibited faster kinematics for a given appendage size than non-smashers.

\section{Modeling approaches to the hydrodynamics of fast rotations}

The simplified approach of a blade-element analysis adequately approximated hydrodynamic drag when compared to a computational fluid dynamic model. Our CFD model indicated regional variation in flow, pressure, and hydrodynamic torque that was not predicted by the blade-element model (Fig. 5), which treats regions along the length of the structure as independently-operating sources of drag. Despite these discrepancies, as long as the shapedependent coefficients of drag used as input in the blade-element models do not overestimate drag in the case of steady linear flow, the blade-element model will also perform well to predict drag-torque for extremely fast rotations (Fig. 5E,F).

A previous study on the rotating head of a pipefish came to the same conclusion (Van Wassenbergh and Aerts 2008), and our study now demonstrates that this approach is also valid for the more than 15-times higher angular velocities and more than 20-times higher angular accelerations of the fastest appendage strikes of mantis shrimp. A noteworthy discrepancy in the mantis shrimp modeling was that the pattern of local variation in the 
hydrodynamic torque along the length of the appendage was poorly predicted by the current blade-element models compared to the pipefish models (Fig. 5G-I vs. Fig. 9 in Van Wassenbergh \& Aerts 2008). Even the blade-element model of the mantis shrimp appendage that accounted for span-wise flow near the proximal and distal ends (under linear flow conditions) by using locally reduced $C_{\mathrm{d}} S$ during the torque calculations still showed considerable local torque differences when compared with CFD (Fig. 5H). We assume this is caused by another, yet related, simplification of blade-element models, namely the simplified treatment of local angles of attack.

Given that the current blade-element models treat the elements as elliptical cylinders, all surfaces in contact with the water are assumed to be parallel with the long axis. This is not the case in the more realistic CFD model that used frustum segments instead of elliptical cylinders. The multi-frustum model therefore appropriately accounted for variation in the angle of attack of the leading edge of the mantis shrimp appendage during rotation (Fig. 5C): the leading-edge surfaces at the distal end (frustum segments 16-18; Fig. 5A) move nearly parallel with respect to the surrounding water during rotation, while the more proximal leading-edge surfaces (frustum segments 10-15; Fig. 5A) move nearly perpendicularly to the water. This is reflected in the pressure patterns on the surfaces: no positive pressures are exerted by the water on the distal part of the leading edge, while a large zone of positive pressure is located on the more proximal part of the leading edge.

Consequently, the larger discrepancy in local torques in the mantis shrimp model (Fig. 5A) compared to the pipefish is probably due to the larger variation in the angles of attack at the distal part of the rotating structure. This effect will also be less prominent in the spearer mantis shrimp, because of their lower variation in chord lengths along their appendages (Fig. 2). Despite these local torque discrepancies, the overall congruence between the total torque output from CFD and blade element modeling is significant for 
future comparative studies, because it demonstrates that hydrodynamic effects that are inherent to rotational flow do not substantially impact the overall drag-torque over a wide range of angular velocities and accelerations.

Both CFD and blade-element approaches present limitations on how we have modeled drag. These techniques do not account for the effects of a transition to turbulent flow in the boundary layer of the structure. This transition, which for smooth surfaces in steady flow occurs at a $R e$ of about 200,000 , would cause drag coefficients to decrease significantly (Hoerner 1965). However, this critical $R e$ was exceeded by one species $(G$. smithii) and only for a brief period upon attaining maximum speed at the distal tip of the appendage (Table 1). A turbulent transition even in this case appears unlikely. The flow over the appendage is predominantly chord-wise, which suggests that the chord is the appropriate characteristic length for the $R e$ that is predictive of the turbulent transition, which would likely yield a $R e$ value below 200,000.

Our models additionally neglect surface roughness, which may induce a turbulent transition in steady flow at a lower Reynolds number (Re>20 000; Hoerner, 1965). However, flows are far from steady during the strike of mantis shrimp. Studies on flow accelerated from rest in pipes show that the transition to a turbulent boundary layer is delayed and thereby causes the transition to occur at significantly higher Reynolds numbers (Lefebvre and White 1989). Comparing the wake of our accelerated simulations with steady flow simulations from CFD support the notion that the flow corresponds to the patterns of a lower $\operatorname{Re}$ (Suppl. Fig. 5). Unfortunately, the combined effect of surface roughness (decreasing critical $R e$ ) and acceleration from rest (increasing critical $R e$ ) on the transition to a turbulent boundary layer is unknown. Because accelerations are extremely high, and the appendage surfaces relatively smooth, we have assumed that the boundary layer remain laminar for mantis shrimp strikes. 
The suite of approaches taken in this study, including our drag measurements, bladeelement analyses of shape-variant mantis shrimp appendages, and CFD analyses of rotating multi-frustum models, lend strong support to a simplified approach going forward. Furthermore, the similar excursions of strikes across taxa (Suppl. Fig. 2) allow an additional level of comparative analysis that incorporates a similar kinematic profile and thus reduces the need for time-intensive kinematic analyses. Future comparative studies could therefore be performed based primarily on morphology and thereby build on and integrate the substantial understanding of morphological and mechanical evolution of this system (Anderson, et al. 2014; Anderson and Patek 2015; Blanco and Patek 2014; Claverie, et al. 2011; Claverie and Patek 2013; Patek, et al. 2007; Patek, et al. 2013; Rosario and Patek 2015).

\section{The evolution of the raptorial appendage}

Shape variation did not play a major role in drag, which suggests that the notable differences in smashing and spearing appendages can be largely attributed to their divergence in predatory function and morphological robustness for impaling and crushing prey (Anderson, et al. 2014; Anderson, et al. 2016b; Claverie, et al. 2011; Claverie and Patek 2013; deVries, et al. 2012). In only one dimension did shape play a notable role: whether the dactyl was open or closed, the spearers had lower torque due to drag $\left(T_{\mathrm{d}}\right)$ than smashers. In contrast, the smashers experienced greater drag energy and drag torque with an open dactyl than with the dactyl closed in a hammering position (closed dactyl).

The combined effects of size and speed on drag generation were substantial across mantis shrimp. A spearing mantis shrimp's strike encounters comparable drag energy and torque as a smashing mantis shrimp that is an order of magnitude smaller (Fig. 7 B,C). If one considers drag as a proxy for energetic costs, then an upper limit on energy costs may explain 
the apparent evolutionary limits on maximal body size in smashers (Blanco and Patek 2014; Patek 2015). In other words, in order to move extremely fast, smasher appendages must be small. The energetic costs may be even more stringent than evidenced in the present paper which allowed mathematical models of larger appendages to rotate more quickly: a previous hydrodynamic analysis demonstrated that higher displacement strikes intuitively associated with greater speeds (given the longer out-lever of the appendage), actually move more slowly than expected, due to the energetic costs of moving through water (McHenry, et al. 2012). Future comparative analyses that more fully account for energetic costs may pinpoint more subtle variation within and across species that balances the tradeoffs among these key variables.

\section{Conclusions}

Unlike the hydrodynamics of locomotor systems that must balance propulsion with drag reduction, the diversification of feeding structures operate under a different constellation of factors, such as fracture resistance, effective prey capture morphology and the reduction of feeding costs (Anderson, et al. 2016a; Anker, et al. 2006; Full, et al. 1989; Vermeij 1987; Weaver, et al. 2012). This study demonstrates that the shapes of fast, $\mathrm{cm}$-scale predatory structures can diversify with relatively minimal costs within the steep constraints of size and kinematics in the generation of drag. 


\section{Acknowledgements}

We thank E. Murphy and P. Green for their help collecting specimens and to two anonymous reviewers for their constructive feedback. We are grateful for the hospitality and advice

offered by R. Heard during our fieldwork with C. scolopendra.

\section{Competing Interests}

The authors have no competing interests.

\section{Author contributions}

MJM contributed to the design of the project, performed mathematical modeling analyses, made figures and contributed to text generation and editing.

PSLA collected drag flume data, performed drag and PGLS analyses, made figures, and contributed to writing sections of the paper.

SVW performed the Computational Fluid Dynamics analyses and contributed to figures and text.

DGM collected and analyzed $C$. scolopendra kinematics and contributed to figures and text. APS helped collect drag flume data and print models.

SNP conceived of the project, performed the cross-species kinematic analyses, made figures, and wrote the paper.

\section{Funding}

Funding was provided by National Science Foundation grants to SNP (IOS-14391050), MJM (IOS-13541042 and IOS-0952344), APS (IOS-1256602) and the John S. Guggenheim

Foundation to SNP. Micro-CT scans were performed at the Center for Nanoscale Systems (CNS) at Harvard University, a member of the National Nanotechnology Infrastructure

Network (NNIN) (NSF ECS-0335765). SVW was supported by the Agence National de la Recherche (ANR-16-ACHN-0006-01). 
All datasets and computer coding are available via Dryad data depository (doi:10.5061/dryad.578j2).

\section{List of Symbols}

$c \quad$ chord length; linear dimension in direction of flow (m)

$C_{d} \quad$ drag coefficient (dimensionless)

$D_{F} \quad \operatorname{drag}(\mathrm{N})$

Edrag energy lost due to drag (J)

$\gamma \quad$ angle of dactyl/propodus rotation (radians)

$h \quad$ width; linear dimension perpendicular to flow (m)

$i \quad$ element number

$k \quad$ shape coefficient (dimensionless)

$l \quad$ thickness; linear dimension along the longitudinal axis of the structure $(\mathrm{m})$

$L \quad$ characteristic length (m)

$\mu \quad$ dynamic viscosity (Pa s)

n number of elements

$r \quad$ distance to pivot point (m)

Re Reynolds number (dimensionless)

$\rho \quad$ density $\left(\mathrm{kg} \mathrm{m}^{-3}\right)$

$S \quad$ surface area $\left(\mathrm{m}^{2}\right)$

$\tau \quad$ drag torque $(\mathrm{N})$

$t \quad$ time (s)

$T \quad$ strike duration (s) 
$T_{d} \quad$ drag-torque index (dimensionless)

$U \quad$ velocity of fluid in flume $\left(\mathrm{m} \mathrm{s}^{-1}\right)$

$v \quad$ velocity of object relative to fluid $\left(\mathrm{m} \mathrm{s}^{-1}\right)$ 


\section{Figure Legends}

Figure 1. Stomatopod appendages vary in shape, size and strike kinematics, depending on their predatory strategies. A) Lysiosquillina maculata ambushes evasive prey using spines on the dactyl and propodus. B) In spearers, the dactyl and propodus form a rotating unit during a strike, most often with the dactyl open and extended toward the prey. These physical models, scaled up to match the Reynolds number of an actual strike, were positioned in the flume with the dactyl either closed against the propodus (left) or opened away from the propodus (right). C) Gonodactylus smithii smashes hard-shelled prey using a bulbous hammer at the base of the dactyl. D) Hammering occurs with the dactyl folded against the propodus (left), but these animals can stab with the dactyl in the open position (right). The physical models (B, D) were placed in the dactyl-open and dactyl-closed orientations for the flume tests. Scale bars are $10 \mathrm{~mm}$. Drawings in A and C are adapted from deVries et al (2012) and Caldwell and Dingle (1976), respectively.

Figure 2. Drag was measured using ten appendage models from five taxa (A), with the dactyls oriented in both open (B) and closed (C) positions. The effect of cross-sectional shape (D) was assessed through direct measurements on the appendages with the dactyl closed and through comparison to an elliptical cylinder. Propodus length (black line) and striking body length (orange line) are indicated on the photo of C. scolopendra. Appendage models were scaled up from their actual size to maintain a constant Reynolds number in the flume experiments. Silhouettes and images are not to scale.

Figure 3. Drag was measured experimentally using physical models placed in a flume.

The vertical rod acted as a lever, which rotates around a beam suspended above the water. The model was affixed to the bottom of the rod. The water flow pushed on the model and rotated the rod. The rod made contact with the force gauge when rotated, thereby measuring the force produced by the flow. A) A schematic of the experimental set-up. B) A labeled photograph of the experimental set-up. 
Figure 4. Using kinematic data across six stomatopod species, the striking body length (the distance from the dactyl-propodus joint to the attachment point of the lateral extensor muscle onto the carpus; Fig. 2) exhibited a significantly negative relationship with angular velocity and acceleration. Each data point represents the maximum value from each individual within each species. The overlaid regression lines were calculated using Phylogenetic Generalized Least Squares based on mean values for each species and the phylogenetic relationships of these taxa.

\section{Figure 5. Computational fluid dynamics analyses simulated the hydrodynamics along a} multi-frustum model matched to the dimensions of a mantis shrimp (Supp. Fig. 3). A. Patterns of steady, linear flow (20 $\mathrm{m} \mathrm{s}^{-1}$ from top to bottom) along a midsagittal plane and the associated pressure on the appendage surfaces are shown in the top panel, and a comparison of drag coefficients calculated on the separate frustum segments (red circles) with those from the literature for long elliptical cylinders of the corresponding aspect ratio (blue circles) are shown in the bottom panel. The black arrowheads show the 3D flow direction. B. Flow velocity from the simulation of constant rotational acceleration is shown along the medial rotational plane. C. Pressure on the surface of the rotating multi-frustum model. Velocities and pressures are shown for three instants (simulation times shown on the left of B). D-F. The resistive torque about the joint from the water exerted on the elliptical cylinder as calculated by CFD (black curve) was compared with the torque calculated analytically using the blade-element model from Van Wassenbergh et al. (2008). Three variations of this model are shown: D, the original model that uses drag coefficients for long elliptical cylinders (see Eq. 5); E, a model that uses the local (i.e., per individual frustum segment) drag coefficients calculated by the steady-flow CFD simulation shown in A; F, a model that combines the information of the overall drag force on the appendage in steady, linear flow (from the CFD simulation shown in A) with the local aspect-ratio dependence from Eq.5. G-I. Local resistive torques at the final simulation time $(0.700 \mathrm{~ms})$ are compared between CFD (black bars) and the blade-element models (colored bars). Torque sign definition is indicated at the bottom of the contour plots. 
Figure 6. In order to compare the empirical and analytical results, drag at varying flow speeds was determined from three sources: empirical flume measurements, drag equations with coefficients set to match appendage shape and orientation, and drag calculations using a simple shape. Drag relative to flow speed was measured in the flume using scale models in open and closed dactyl positions (blue and red dots, respectively). The calculated drag was fit to the flume data using linear least-squares regression (solid lines overlaying dots). The open-dactyl configuration yielded higher drag than the closed-dactyl orientation in all species except for the spearers, which exhibited minimal drag differences in the open and closed dactyl configurations. Using the same drag calculations, but with a drag coefficient for cylinders with elliptical (gray lines) cross-sections, the elliptical cylinders provided a lower bound to the flume-based drag measurements.

Figure 7. Drag energy (A-C) and maximum torque (D-F) were variably sensitive to real and simulated shifts in strike duration, propodus length and drag-torque index across species (blue: smasher G. smithii; green: spearer C. scolopendra; purple: spearer $L$. maculata). Both metrics were extremely sensitive to size $(\mathrm{B}, \mathrm{E})$ such that small shifts in propodus length yielded many orders of magnitude of change in torque and drag energy that affected the three appendage types similarly. Compared to these strong effects of size, dragtorque index (DTI) followed less-overlapping and less-steep increments in drag energy and torque across shifts in DTI. L. maculata experienced a relatively smaller shift in drag energy across similar strike duration ranges than experienced by the other two species. The greater effect of the dactyl opening in smashers is visible via the offset between the dactyl open simulation (white square) and the closed simulation (solid circle). Note that higher strike duration indicates a slower strike (i.e., lower velocity and acceleration) and that the appendage photographs are not to scale. 


\section{Works Cited}

Anderson PSL, Claverie T, Patek SN. 2014. Levers and linkages: mechanical trade-offs in a power-amplified system. Evolution 68(7):1919-1414.

Anderson PSL, LaCosse J, Pankow M. 2016a. Point of impact: the effect of size and speed on puncture mechanics. Interface Focus 6(3).

Anderson PSL, Patek SN. 2015. Mechanical sensitivity reveals evolutionary dynamics of mechanical systems. Proceedings of the Royal Society of London B: Biological Sciences 282(1804):1-9.

Anderson PSL, Smith DC, Patek SN. 2016b. Competing influences on morphological modularity in biomechanical systems: a case study in mantis shrimp. Evolution \& Development 18(3):171-181.

Anker A, Ahyong ST, Noel PY, Palmer AR. 2006. Morphological phylogeny of alpheid shrimps: parallel preadaptation and the origin of a key morphological innovation, the snapping claw Evolution 60(12):2507-2528.

Batchelor GK. 1967. An Introduction to Fluid Dynamics: Cambridge University Press.

Blanco MM, Patek SN. 2014. Muscle trade-offs in a power-amplified prey capture system. Evolution 68(5):1399-1414.

Caldwell RL, Dingle H. 1976. Stomatopods. Scientific American 234(1):81-89.

Claverie T, Chan E, Patek SN. 2011. Modularity and scaling in fast movements: power amplification in mantis shrimp. Evolution 62(2):443-461.

Claverie T, Patek SN. 2013. Modularity and rates of evolutionary change in a poweramplified prey capture system. Evolution 67(11):3191-3207.

Cox SM, Schmidt D, Modarres-Sadeghi Y, Patek SN. 2014. A physical model of the extreme mantis shrimp strike: kinematics and cavitation of Ninjabot. Bioinspiration \& Biomimetics 9(1):1-16.

deVries MS, Murphy EAK, Patek SN. 2012. Strike mechanics of an ambush predator: the spearing mantis shrimp. Journal of Experimental Biology 215:4374-4384.

Dickinson MH, Lehmann F-O, Sane SP. 1999. Wing rotation and the aerodynamic basis of insect flight. Science 284(5422):1954-1960.

Fish FE. 1984. Mechanics, power output and efficiency of the swimming muskrat (Ondatra zibethicus). Journal of Experimental Biology 110(1):183-201.

Full RJ, Caldwell RL, Chow SW. 1989. Smashing energetics: prey selection and feeding efficiency of the stomatopod, Gonodactylus bredini. Ethology 81:134-147.

Goyens J, Van Wassenbergh S, Dirckx J, Aerts P. 2015. Cost of flight and the evolution of stag beetle weaponry. Journal of The Royal Society Interface 12(106).

Hoerner SF. 1965. Fluid-Dynamic Drag. Brick Town, New Jersey: Author. 
Jiang H, Kiørboe T. 2011. Propulsion efficiency and imposed flow fields of a copepod jump. Journal of Experimental Biology 214(3):476-486.

Johansson LC, Lauder GV. 2004. Hydrodynamics of surface swimming in leopard frogs (Rana pipiens). Journal of Experimental Biology 207(22):3945-3958.

Kagaya K, Patek SN. 2016. Feed-forward motor control of ultrafast, ballistic movements. Journal of Experimental Biology 219(3):319-333.

Koehl MAR. 1996. When does morphology matter? Annual Review of Ecology and Systematics 27:501-542.

Lefebvre PJ, White FM. 1989. Experiments on transition to turbulence in a constantacceleration pipe flow. Journal of Fluids Engineering 111(4):428-432.

Lentink D, Dickson WB, van Leeuwen JL, Dickinson MH. 2009. Leading-edge vortices elevate lift of autorotating plant seeds. Science 324(5933):1438-1440.

Li G, Müller UK, van Leeuwen JL, Liu H. 2012. Body dynamics and hydrodynamics of swimming fish larvae: a computational study. Journal of Experimental Biology 215(22):4015-4033.

Liu H, Wassersug R, Kawachi K. 1996. A computational fluid dynamics study of tadpole swimming. Journal of Experimental Biology 199(6):1245-1260.

McHenry MJ, Azizi E, Strother JA. 2003. The hydrodynamics of locomotion at intermediate Reynolds numbers: undulatory swimming in ascidian larvae (Botrylloides sp.). Journal of Experimental Biology 206(2):327-343.

McHenry MJ, Claverie T, Rosario MV, Patek SN. 2012. Gearing for speed slows the predatory strike of a mantis shrimp. Journal of Experimental Biology 215:1231-1245.

Menter FR. 1994. Two-equation eddy-viscosity turbulence models for engineering applications. AIAA Journal 32(8):1598-1605.

Nakata T, Liu H, Bomphrey RJ. 2015. A CFD-informed quasi-steady model of flapping-wing aerodynamics. Journal of Fluid Mechanics 783:323-343.

Ngo V, McHenry MJ. 2014. The hydrodynamics of swimming at intermediate Reynolds numbers in the water boatman (Corixidae). Journal of Experimental Biology 217:2740-2751.

Orme D, Freckleton R, Thomas G, Petzoldt T, Fritz S, Isaac N, Pearse W. 2012. caper: Comparative Analyses of Phylogenetics and Evolution in R. Version 0.5.

Patek SN. 2015. The most powerful movements in biology. American Scientist 103(5):330337.

Patek SN, Caldwell RL. 2005. Extreme impact and cavitation forces of a biological hammer: strike forces of the peacock mantis shrimp (Odontodactylus scyllarus). Journal of Experimental Biology 208:3655-3664.

Patek SN, Korff WL, Caldwell RL. 2004. Deadly strike mechanism of a mantis shrimp. Nature 428:819-820.

Patek SN, Nowroozi BN, Baio JE, Caldwell RL, Summers AP. 2007. Linkage mechanics and power amplification of the mantis shrimp's strike. Journal of Experimental Biology 210:3677 - 3688 . 
Patek SN, Rosario MV, Taylor JRA. 2013. Comparative spring mechanics in mantis shrimp. Journal of Experimental Biology 215:1317-1329.

Porter ML, Zhang Y, Desai S, Caldwell RL, Cronin TW. 2010. Evolution of anatomical and physiological specialization in the compound eyes of stomatopod crustaceans. Journal of Experimental Biology 213:3473-3486.

R_Core_Team. 2014. R: A language and environment for statistical computing. Vienna, Austria: R Foundation for Statistical Computing.

Richards CT. 2010. Kinematics and hydrodynamics analysis of swimming anurans reveals striking inter-specific differences in the mechanism for producing thrust. Journal of Experimental Biology 213(4):621-634.

Rosario MV, Patek SN. 2015. Multi-level analysis of elastic morphology: the mantis shrimp's spring. Journal of Morphology 276:1123-1135.

Tanaka Y, Hisada M. 1980. The hydraulic mechanism of the predatory strike in dragonfly larvae. Journal of Experimental Biology 88:1-19.

Van Wassenbergh S, Aerts P. 2008. Rapid pivot feeding in pipefish: flow effects on prey and evaluation of simple dynamic modelling via computational fluid dynamics. Journal of The Royal Society Interface 5(28):1291-1301.

Van Wassenbergh S, Day SW, Hernandez PL, Higham TE, Skorczewski T. 2015a. Suction power output and the intertial cost of rotating the neurcranium to generate suction in fish. Journal of Theoretical Biology 372:159-167.

Van Wassenbergh S, Strother JA, Flammang BE, Ferry-Graham LA, Aerts P. 2008. Extremely fast prey capture in pipefish is powered by elastic recoil. Journal of the Royal Society Interface 5:285-296.

Van Wassenbergh S, van Manen K, Marcroft TA, Alfaro ME, Stamhuis EJ. 2015b. Boxfish swimming paradox resolved: forces by the flow of water around the body promote manoeuvrability. Journal of the Royal Society Interface 12(103):20141146.

Vermeij GJ. 1987. Evolution and escalation: an ecological history of life. Princeton: Princeton University Press. 527 p.

Versluis M, Schmitz B, von der Heydt A, Lohse D. 2000. How snapping shrimp snap: through cavitating bubbles. Science 289:2114-2117.

Walker JA. 2002. Rotational lift: something different or more of the same? Journal of Experimental Biology 205(24):3783-3792.

Walker JA. 2004. Dynamics of pectoral fin rowing in a fish with an extreme rowing stroke: the threespine stickleback (Gasterosteus aculeatus). Journal of Experimental Biology 207(11):1925-1939.

Weaver JC, Milliron GW, Miserez A, Evans-Lutterodt K, Herrera S, Gallana I, Mershon WJ, Swanson B, Zavattieri P, DiMasi E and others. 2012. The stomatopod dactyl club: a formidable damage-tolerant biological hammer. Science 336(6086):1275-1280.

Webb PW, Blake RW. 1985. Swimming. In: Hildebrand M, Bramble DM, Liem KF, Wake DB, editors. Functional Vertebrate Morphology. Cambridge, MA: Belknap Press. 


\section{Figures}
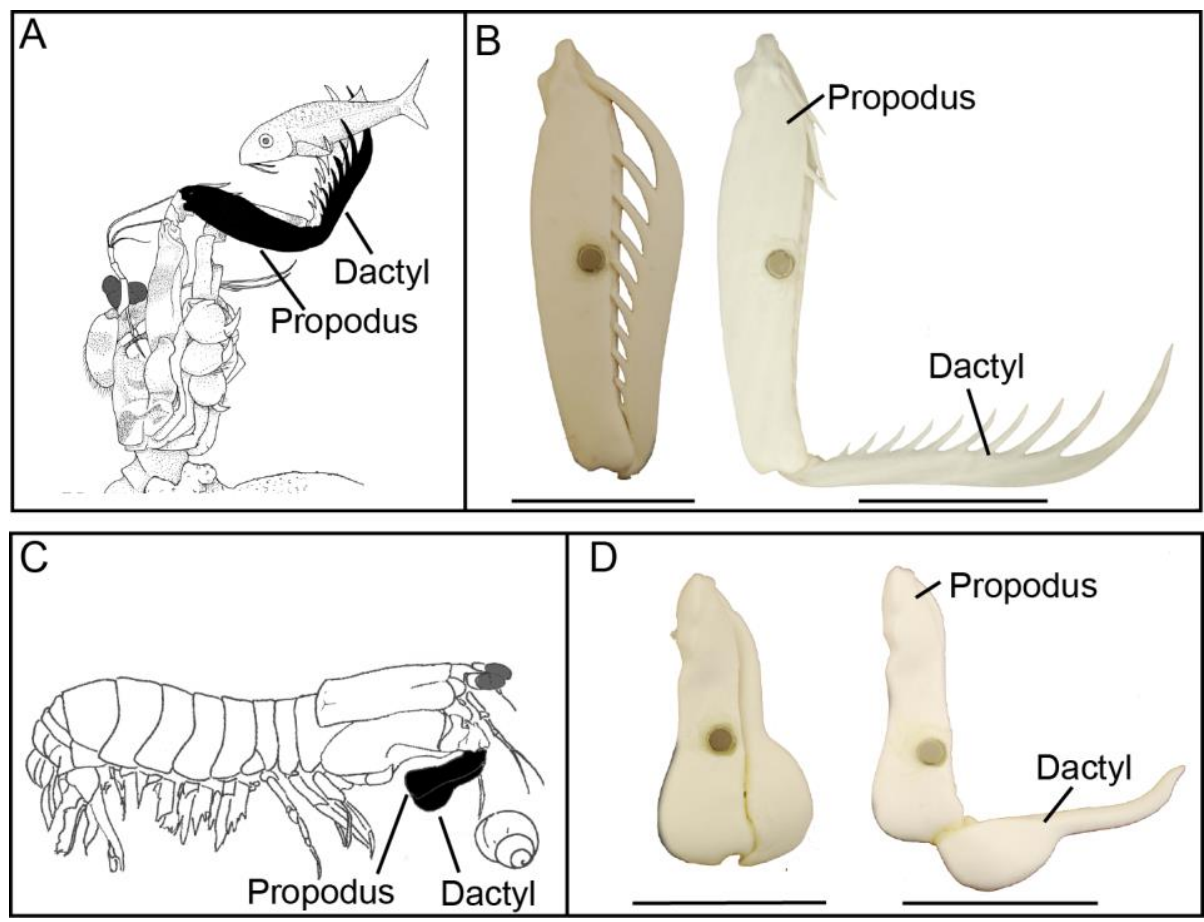

Figure 1. Stomatopod appendages vary in shape, size and strike kinematics, depending on their predatory strategies. A) Lysiosquillina maculata ambushes evasive prey using spines on the dactyl and propodus. B) In spearers, the dactyl and propodus form a rotating unit during a strike, most often with the dactyl open and extended toward the prey. These physical models, scaled up to match the Reynolds number of an actual strike, were positioned in the flume with the dactyl either closed against the propodus (left) or opened away from the propodus (right). C) Gonodactylus smithii smashes hard-shelled prey using a bulbous hammer at the base of the dactyl. D) Hammering occurs with the dactyl folded against the propodus (left), but these animals can stab with the dactyl in the open position (right). The physical models (B, D) were placed in the dactyl-open and dactyl-closed orientations for the flume tests. Scale bars are $10 \mathrm{~mm}$. Drawings in A and C are adapted from deVries et al (2012) and Caldwell and Dingle (1976), respectively. 


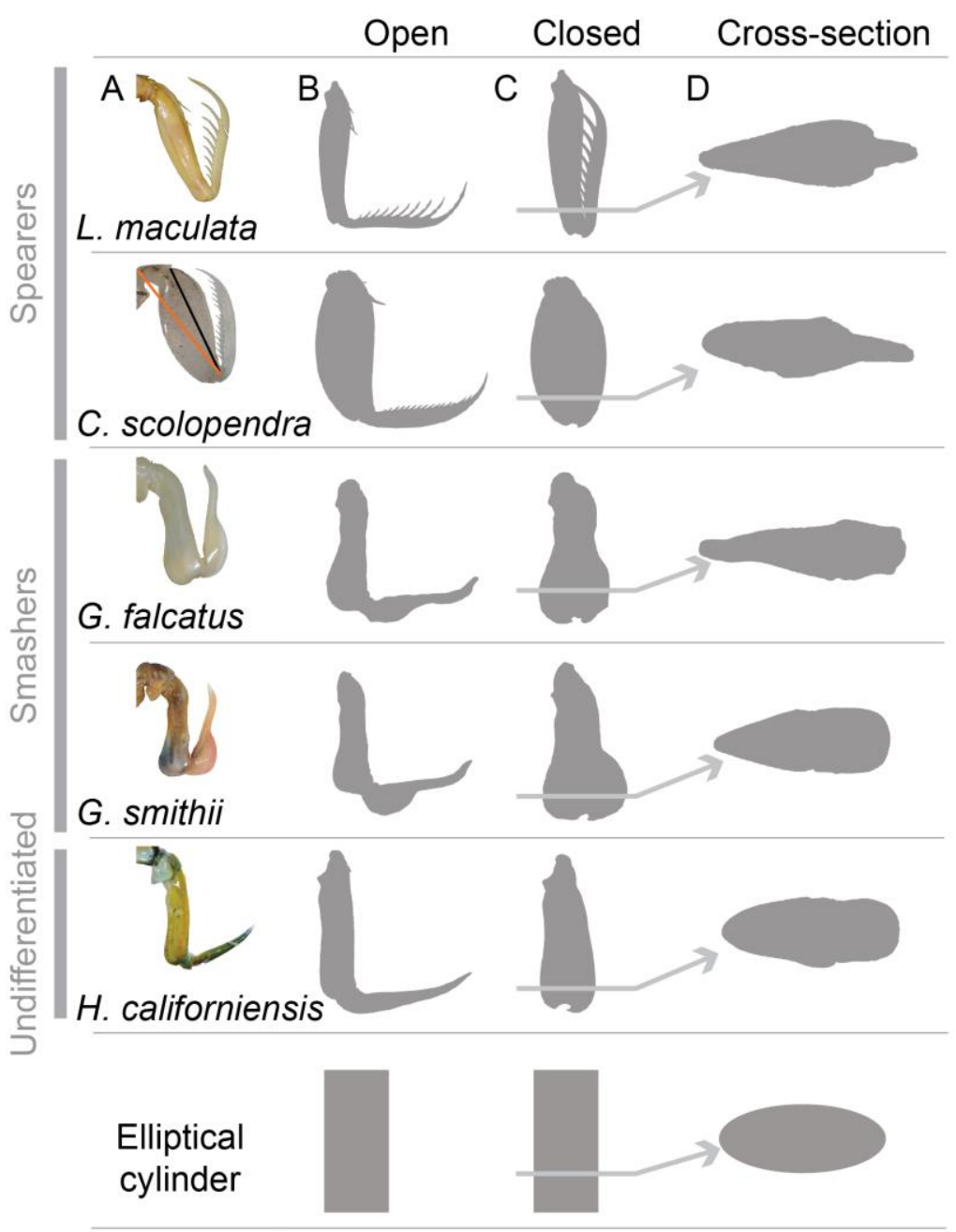

Figure 2. Drag was measured using ten appendage models from five taxa (A), with the dactyls oriented in both open (B) and closed (C) positions. The effect of cross-sectional shape (D) was assessed through direct measurements on the appendages with the dactyl closed and through comparison to an elliptical cylinder. Propodus length (black line) and striking body length (orange line) are indicated on the photo of C. scolopendra. Appendage models were scaled up from their actual size to maintain a constant Reynolds number in the flume experiments. Silhouettes and images are not to scale. 


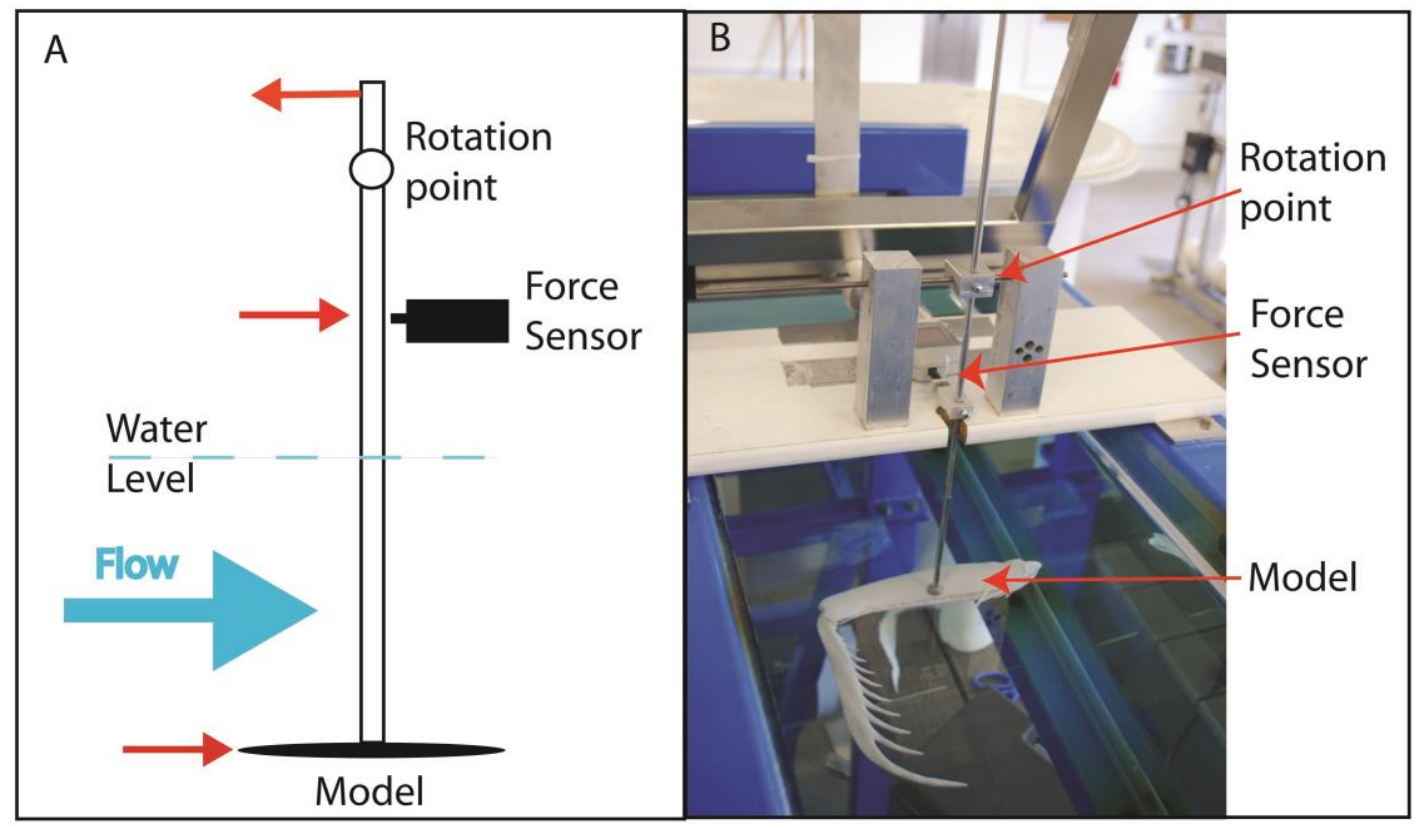

Figure 3. Drag was measured experimentally using physical models placed in a flume.

The vertical rod acted as a lever, which rotates around a beam suspended above the water. The model was affixed to the bottom of the rod. The water flow pushed on the model and rotated the rod. The rod made contact with the force gauge when rotated, thereby measuring the force produced by the flow. A) A schematic of the experimental set-up. B) A labeled photograph of the experimental set-up. 

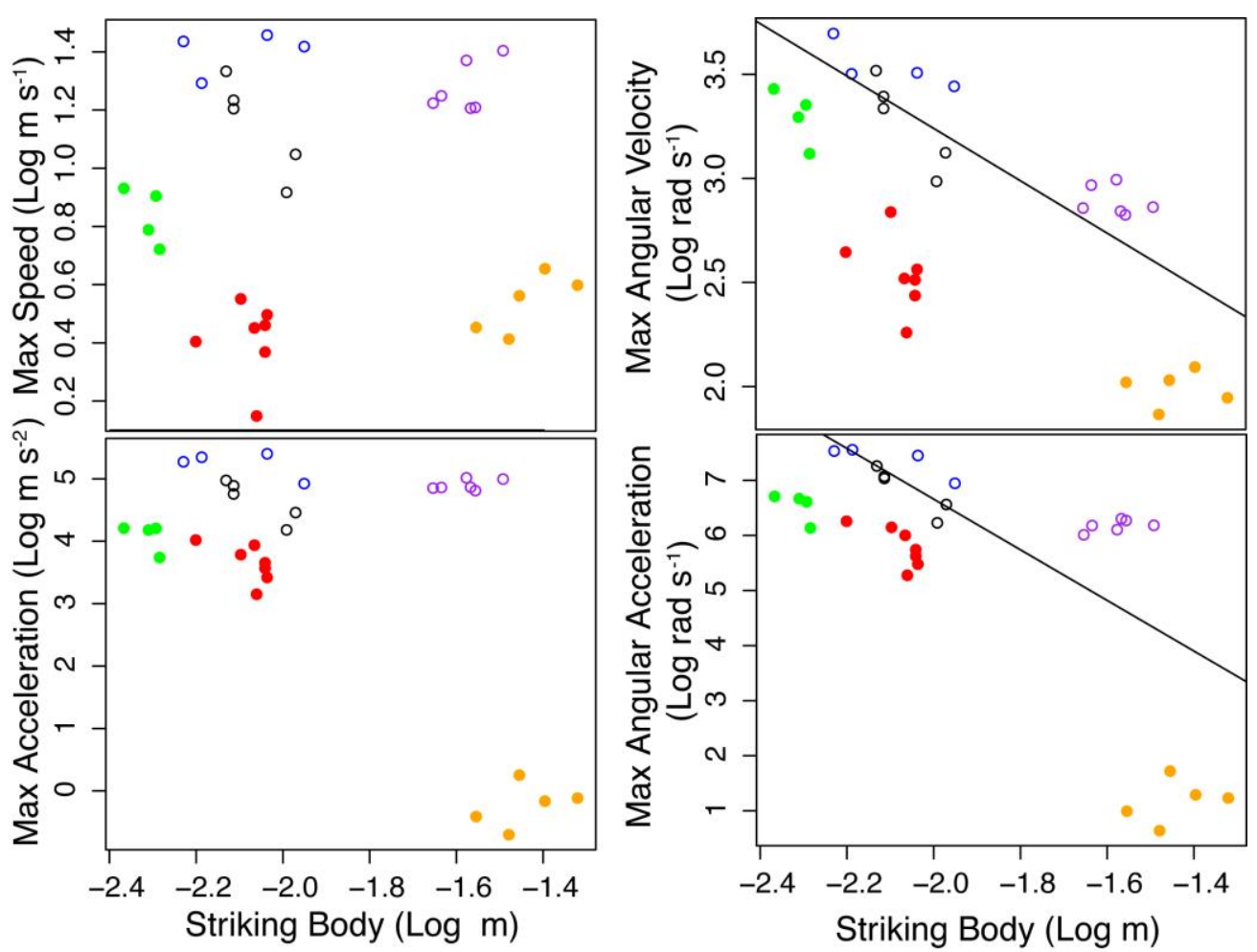

\begin{tabular}{|cc|}
\hline Spearers & Smashers \\
A.vicina & O G.smithii \\
C.scolopendra O N.bredini \\
L.maculata & OO.scyllarus \\
\hline
\end{tabular}

Figure 4. Using kinematic data across six stomatopod species, the striking body length (the distance from the dactyl-propodus joint to the attachment point of the lateral extensor muscle onto the carpus; Fig. 2) exhibited a significantly negative relationship with angular velocity and acceleration. Each data point represents the maximum value from each individual within each species. The overlaid regression lines were calculated using Phylogenetic Generalized Least Squares based on mean values for each species and the phylogenetic relationships of these taxa. 
A
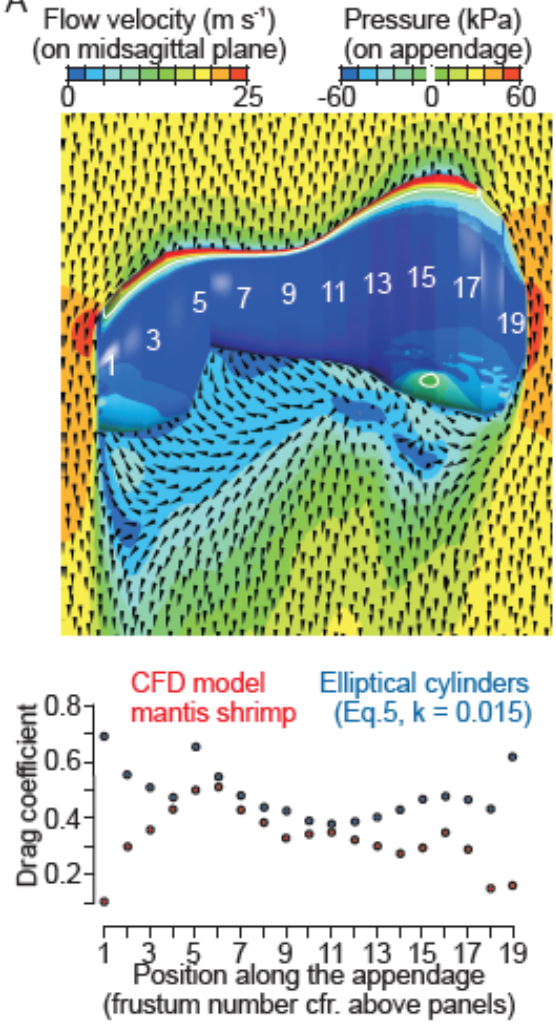

D

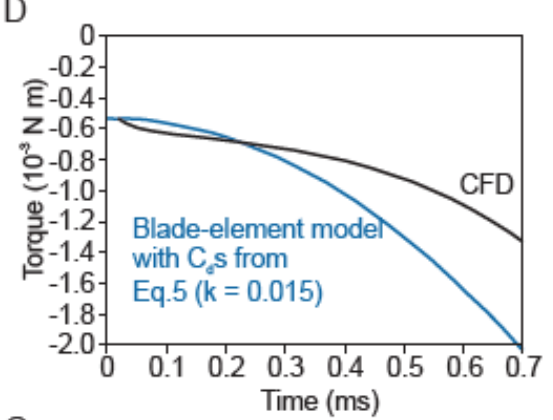

G

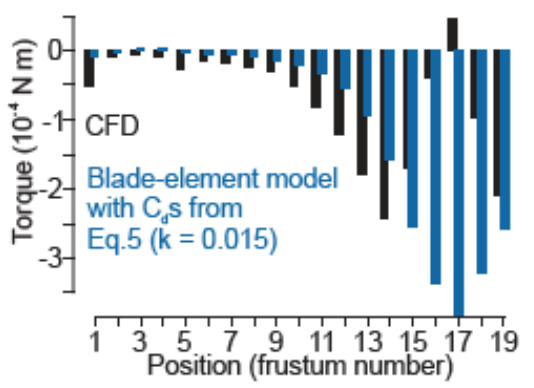

B
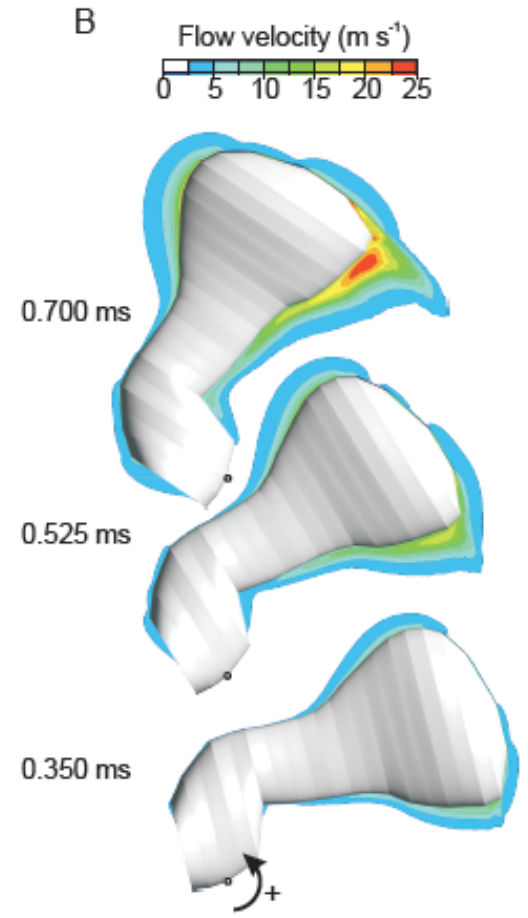

C Pressure (kPa) $-60-36-12 \quad 12 \quad 3660$

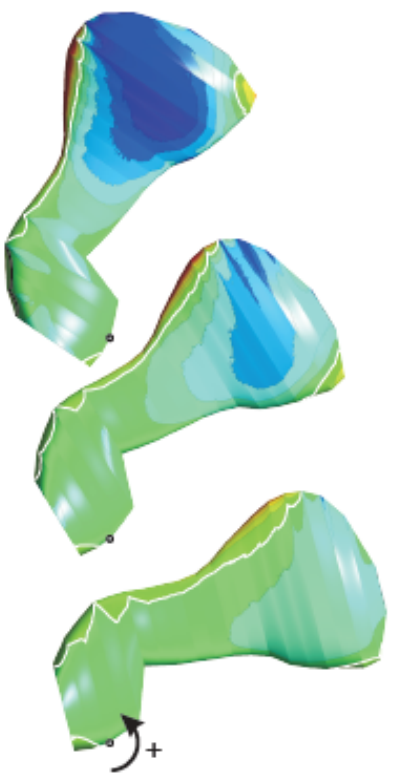

E

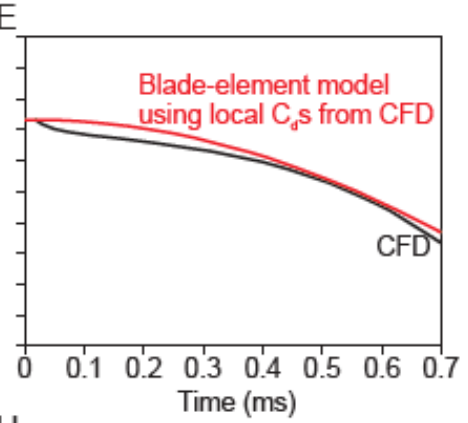

$\mathrm{H}$
$\mathrm{F}$

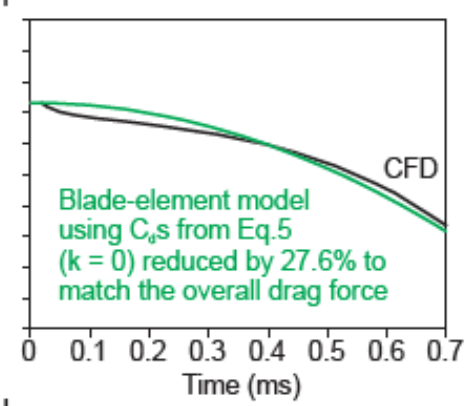

I 
Figure 5. Computational fluid dynamics analyses simulated the hydrodynamics along a multi-frustum model matched to the dimensions of a mantis shrimp (Supp. Fig. 3). A. Patterns of steady, linear flow (20 $\mathrm{m} \mathrm{s}^{-1}$ from top to bottom) along a midsagittal plane and the associated pressure on the appendage surfaces are shown in the top panel, and a comparison of drag coefficients calculated on the separate frustum segments (red circles) with those from the literature for long elliptical cylinders of the corresponding aspect ratio (blue circles) are shown in the bottom panel. The black arrowheads show the 3D flow direction. B. Flow velocity from the simulation of constant rotational acceleration is shown along the medial rotational plane. C. Pressure on the surface of the rotating multi-frustum model. Velocities and pressures are shown for three instants (simulation times shown on the left of B). D-F. The resistive torque about the joint from the water exerted on the elliptical cylinder as calculated by CFD (black curve) was compared with the torque calculated analytically using the blade-element model from Van Wassenbergh et al. (2008). Three variations of this model are shown: D, the original model that uses drag coefficients for long elliptical cylinders (see Eq. 5); E, a model that uses the local (i.e., per individual frustum segment) drag coefficients calculated by the steady-flow CFD simulation shown in A; F, a model that combines the information of the overall drag force on the appendage in steady, linear flow (from the CFD simulation shown in A) with the local aspect-ratio dependence from Eq.5. G-I. Local resistive torques at the final simulation time $(0.700 \mathrm{~ms})$ are compared between CFD (black bars) and the blade-element models (colored bars). Torque sign definition is indicated at the bottom of the contour plots. 


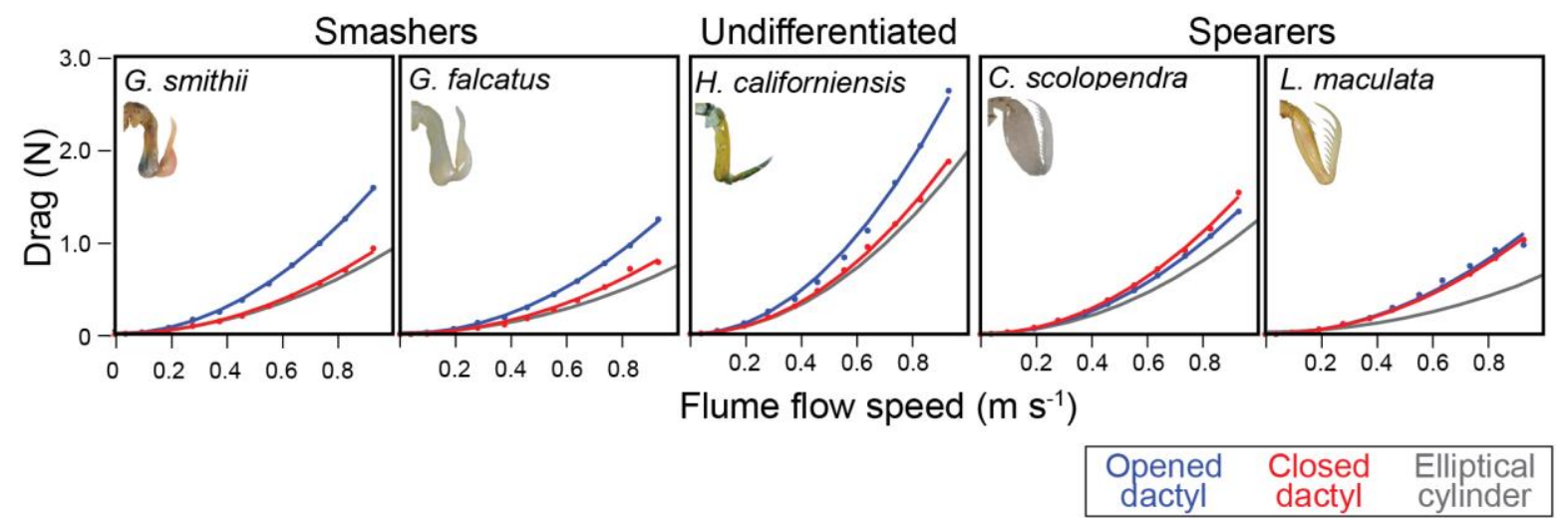

Figure 6. In order to compare the empirical and analytical results, drag at varying flow speeds was determined from three sources: empirical flume measurements, drag equations with coefficients set to match appendage shape and orientation, and drag calculations using a simple shape. Drag relative to flow speed was measured in the flume using scale models in open and closed dactyl positions (blue and red dots, respectively). The calculated drag was fit to the flume data using linear least-squares regression (solid lines overlaying dots). The open-dactyl configuration yielded higher drag than the closed-dactyl orientation in all species except for the spearers, which exhibited minimal drag differences in the open and closed dactyl configurations. Using the same drag calculations, but with a drag coefficient for cylinders with elliptical (gray lines) cross-sections, the elliptical cylinders provided a lower bound to the flume-based drag measurements. 

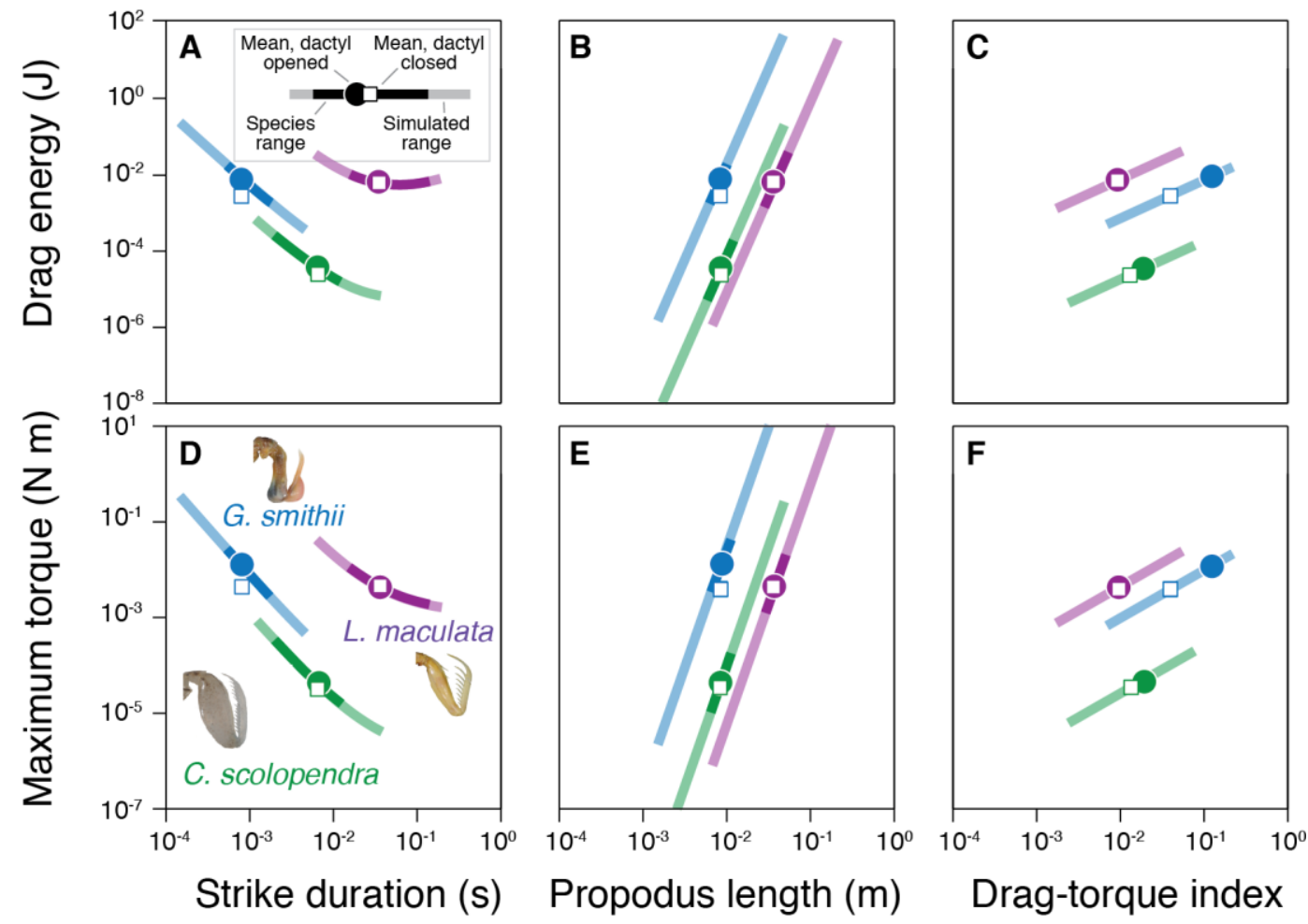

Propodus length $(m)$

Drag-torque index

Figure 7. Drag energy (A-C) and maximum torque (D-F) were variably sensitive to real and simulated shifts in strike duration, propodus length and drag-torque index across species (blue: smasher G. smithii; green: spearer $C$. scolopendra; purple: spearer $L$. maculata). Both metrics were extremely sensitive to size $(\mathrm{B}, \mathrm{E})$ such that small shifts in propodus length yielded many orders of magnitude of change in torque and drag energy that affected the three appendage types similarly. Compared to these strong effects of size, dragtorque index (DTI) followed less-overlapping and less-steep increments in drag energy and torque across shifts in DTI. L. maculata experienced a relatively smaller shift in drag energy across similar strike duration ranges than experienced by the other two species. The greater effect of the dactyl opening in smashers is visible via the offset between the dactyl open simulation (white square) and the closed simulation (solid circle). Note that higher strike duration indicates a slower strike (i.e., lower velocity and acceleration) and that the appendage photographs are not to scale. 
Table 1. Raptorial appendage size and kinematics across six mantis shrimp species.

\begin{tabular}{|c|c|c|c|c|c|c|}
\hline & $\begin{array}{l}\text { Neogonodactylus } \\
\text { bredini }\end{array}$ & $\begin{array}{l}\text { Odontodactylus } \\
\text { scyllarus }\end{array}$ & $\begin{array}{l}\text { Gonodactylus } \\
\text { smithii }\end{array}$ & $\begin{array}{l}\text { Lysiosquillina } \\
\text { maculata }\end{array}$ & $\begin{array}{c}\text { Coronis } \\
\text { scolopendra }\end{array}$ & Alachosquilla vicina \\
\hline Raptorial appendage type & smasher & smasher & smasher & spearer & spearer & spearer \\
\hline $\begin{array}{c}\text { Sample size (\# } \\
\text { individuals: } \\
\text { strikes/individual) }\end{array}$ & 5: $11-24$ & $6: 7-11$ & $5: 10$ & $5: 3-7$ & $7: 5-10$ & $4-5: 1-12$ \\
\hline Propodus length $(\mathrm{cm})$ & $\begin{array}{c}0.78 \pm 0.18(0.58- \\
1.00)\end{array}$ & $\begin{array}{c}2.46 \pm 0.33(2.02- \\
2.95)\end{array}$ & $\begin{array}{c}0.73 \pm 0.18(0.54- \\
0.96)\end{array}$ & $\begin{array}{c}3.48 \pm 0.79(2.59- \\
4.71)\end{array}$ & $\begin{array}{c}0.76 \pm 0.09(0.56- \\
0.83)\end{array}$ & $\begin{array}{c}0.42 \pm 0.03(0.38- \\
0.46)\end{array}$ \\
\hline Striking body length $(\mathrm{cm})$ & $\begin{array}{c}0.87 \pm 0.16(0.74- \\
1.07)\end{array}$ & $\begin{array}{c}2.65 \pm 0.36(2.22- \\
3.22)\end{array}$ & $\begin{array}{c}0.82 \pm 0.25(0.59- \\
1.12)\end{array}$ & $\begin{array}{c}3.68 \pm 0.75(2.79- \\
4.78)\end{array}$ & $\begin{array}{c}0.84 \pm 0.10(0.63- \\
0.92)\end{array}$ & $\begin{array}{c}0.48 \pm 0.04(0.43- \\
0.52)\end{array}$ \\
\hline Speed $\left(\mathrm{m} \mathrm{s}^{-1}\right)$ & $11.3 \pm 4.9(2.8-21.6)$ & $14.0 \pm 1.8(4.5-25.4)$ & $20.2 \pm 4.1(7.2-30.6)$ & $2.3 \pm 0.5(1.2-4.5)$ & $2.1 \pm 0.6(0.7-3.6)$ & $5.7 \pm 0.9(4.0-8.5)$ \\
\hline Angular velocity $\left(\operatorname{rad~s}^{-1}\right)$ & $\begin{array}{c}1585 \pm 755(379- \\
3298)\end{array}$ & $605 \pm 51(163-987)$ & $\begin{array}{c}2821 \pm 682(1175- \\
4976)\end{array}$ & $\begin{array}{c}64.7 \pm 13.9(25.7- \\
124.3)\end{array}$ & $296 \pm 149(93-690)$ & $\begin{array}{c}1610 \pm 342(1003- \\
2694)\end{array}$ \\
\hline Linear acceleration $\left(\mathrm{m} \mathrm{s}^{-2}\right)$ & $\begin{array}{l}3.6 \times 10^{4} \pm 2.6 \times 10^{4} \\
\left(0.2 \times 10^{4}-9.5 \times 10^{4}\right)\end{array}$ & $\begin{array}{c}5.6 \times 10^{4} \pm 7300 \\
\left(2.0 \times 10^{4}-1.0 \times 10^{5}\right)\end{array}$ & $\begin{array}{l}7.8 \times 10^{4} \pm 2.4 \times 10^{4} \\
\left(2.0 \times 10^{4}-2.5 \times 10^{5}\right)\end{array}$ & $\begin{array}{c}0.29 \pm 0.14(0.04- \\
1.80)\end{array}$ & $\begin{array}{c}2600 \pm 1200(300- \\
\left.1.1 \times 10^{4}\right)\end{array}$ & $\begin{array}{c}9100 \pm 3300(1300- \\
\left.1.6 \times 10^{4}\right)\end{array}$ \\
\hline $\begin{array}{c}\text { Angular acceleration (rad } \\
\left.\qquad \mathbf{s}^{-2}\right)\end{array}$ & $\begin{array}{l}5.8 \times 10^{6} \pm 4.4 \times 10^{6} \\
\left(2.4 \times 10^{5}-1.8 \times 10^{7}\right)\end{array}$ & $\begin{array}{l}9.4 \times 10^{5} \pm 9.6 \times 10^{4} \\
\left(2.1 \times 10^{5}-2.0 \times 10^{6}\right)\end{array}$ & $\begin{array}{l}1.1 \times 10^{7} \pm 5.3 \times 10^{6} \\
\left(3.2 \times 10^{6}-3.6 \times 10^{7}\right)\end{array}$ & $\begin{array}{c}8.3 \pm 4.4(1.1- \\
53.0)\end{array}$ & $\begin{array}{l}3.9 \times 10^{5} \pm 2.9 \times 10^{5} \\
\left(3.6 \times 10^{4}-1.8 \times 10^{6}\right)\end{array}$ & $\begin{array}{l}2.6 \times 10^{6} \pm 1.0 \times 10^{6} \\
\left(3.3 \times 10^{5}-5.1 \times 10^{6}\right)\end{array}$ \\
\hline Duration $\left(10^{-3} \mathrm{~s}\right)$ & NA & $2.7 \pm 0.5(1.6-5.2)$ & $\begin{array}{c}0.84 \pm 0.20(0.28- \\
2.00)\end{array}$ & $\begin{array}{c}34.7 \pm 9.9(20.0- \\
70.0)\end{array}$ & $6.7 \pm 2.2(2.3-13.1)$ & $3.3 \pm 0.4(1.9-4.5)$ \\
\hline $\begin{array}{l}\text { Time to maximum speed } \\
\qquad\left(10^{-3} \mathrm{~s}\right)\end{array}$ & $\begin{array}{c}1.14 \pm 0.56(0.54- \\
2.89)\end{array}$ & NA & $\begin{array}{c}0.72 \pm 0.17(0.27- \\
1.43)\end{array}$ & $\begin{array}{c}15.5 \pm 5.4(10.0- \\
40.0)\end{array}$ & $2.7 \pm 1.0(0.2-6.1)$ & $1.1 \pm 0.2(0.7-1.5)$ \\
\hline
\end{tabular}




\begin{tabular}{|c|c|c|c|c|c|c|}
\hline $\begin{array}{l}\text { Imaging rate (frames per } \\
\text { second) }\end{array}$ & 30000 & 5000 & 30000 & 3000 & $10000-15000$ & 10000 \\
\hline Reynolds Number & $9.3 \times 10^{\wedge} 4$ & $3.5 \times 10^{\wedge} 5$ & $1.6 \times 10^{\wedge} 5$ & $8.0 \times 10^{\wedge} 4$ & $1.7 \times 10^{\wedge} 4$ & $2.6 \times 10^{\wedge} 4$ \\
\hline Source & $\begin{array}{c}\text { Kagaya \& Patek, } \\
2016\end{array}$ & Patek et al 2004 & $\begin{array}{c}\text { Cox et al } 2014 \\
\text { (reanalyzed) }\end{array}$ & $\begin{array}{l}\text { deVries et al } \\
2012 \\
\text { (reanalyzed) }\end{array}$ & this study & deVries et al 2012 \\
\hline
\end{tabular}

Data from the present study and previous studies were compiled to examine the effects of scaling and kinematics on strike energetics. Several datasets were reanalyzed in order to make the analyses consistent across the datasets. Reynolds numbers are calculated based on the instantaneous peak speed and striking body length, both averaged for each species. 
Table 2. Strike kinematics of the medium-sized spearer, Coronis scolopendra.

\begin{tabular}{|c|c|c|c|c|c|c|}
\hline $\begin{array}{l}\text { \# strikes } \\
\text { (\# prey } \\
\text { distance } \\
\text { msmts) }\end{array}$ & $\begin{array}{l}\text { Maximum } \\
\text { linear speed } \\
\quad\left(\mathrm{m} \mathrm{s}^{-1}\right)\end{array}$ & $\begin{array}{l}\text { Maximum } \\
\text { linear } \\
\text { acceleration } \\
\left(\mathbf{1 0}^{3} \mathrm{~m} \mathrm{~s}^{-2}\right)\end{array}$ & $\begin{array}{c}\text { Maximum } \\
\text { angular } \\
\text { velocity } \\
\left(\mathbf{1 0}^{2} \text { rad s }^{-1}\right)\end{array}$ & $\begin{array}{c}\text { Maximum } \\
\text { angular } \\
\text { acceleration } \\
\left(10^{5} \mathrm{rad} \mathrm{s}^{-2}\right)\end{array}$ & $\begin{array}{c}\text { Prey } \\
\text { distance } \\
\left(\mathbf{1 0}^{-3} \mathbf{m}\right)\end{array}$ & $\begin{array}{c}\text { Time to } \\
\text { maximum } \\
\text { linear speed } \\
\left(10^{-3} \mathrm{~s}\right)\end{array}$ \\
\hline $8(7)$ & $\begin{array}{l}2.85 \pm 0.45 \\
(2.19-3.56)\end{array}$ & $\begin{array}{l}3.9 \pm 1.4 \\
(2.3-6.1)\end{array}$ & $\begin{array}{l}5.91 \pm 0.90 \\
(4.58-6.90)\end{array}$ & $\begin{array}{c}8.17 \pm 3.30 \\
(4.81-14.10)\end{array}$ & $\begin{array}{l}6.44 \pm 1.36 \\
(5.03-8.64)\end{array}$ & $\begin{array}{l}1.63 \pm 0.74 \\
(0.20-2.80)\end{array}$ \\
\hline $8(7)$ & $\begin{array}{l}1.96 \pm 0.37 \\
(1.52-2.54)\end{array}$ & $\begin{array}{c}4.5 \pm 3.3 \\
(1.7-10.5)\end{array}$ & $\begin{array}{l}3.49 \pm 0.65 \\
(2.62-4.43) \\
\end{array}$ & $\begin{array}{c}7.90 \pm 5.68 \\
(2.86-18.20) \\
\end{array}$ & $\begin{array}{l}6.24 \pm 1.16 \\
(5.01-8.31) \\
\end{array}$ & $\begin{array}{l}1.46 \pm 0.42 \\
(0.80-2.13)\end{array}$ \\
\hline $7(6)$ & $\begin{array}{l}2.19 \pm 0.68 \\
(1.23-2.89)\end{array}$ & $\begin{array}{l}1.9 \pm 1.4 \\
(0.5-4.5)\end{array}$ & $\begin{array}{l}2.44 \pm 0.80 \\
(1.34-3.26)\end{array}$ & $\begin{array}{l}2.10 \pm 1.71 \\
(0.58-5.55)\end{array}$ & $\begin{array}{c}8.23 \pm 3.21 \\
(3.90-12.80)\end{array}$ & $\begin{array}{l}3.76 \pm 1.28 \\
(2.10-5.70) \\
\end{array}$ \\
\hline $5(4)$ & $\begin{array}{l}1.94 \pm 0.40 \\
(1.39-2.34)\end{array}$ & $\begin{array}{l}2.6 \pm 1.3 \\
(1.1-3.7)\end{array}$ & $\begin{array}{l}2.25 \pm 0.47 \\
(1.57-2.74)\end{array}$ & $\begin{array}{l}3.03 \pm 1.51 \\
(1.24-4.24)\end{array}$ & $\begin{array}{c}8.01 \pm 1.97 \\
(5.33-10.00)\end{array}$ & $\begin{array}{l}3.30 \pm 1.90 \\
(1.20-6.10)\end{array}$ \\
\hline $5(5)$ & $\begin{array}{l}1.78 \pm 0.73 \\
(1.15-2.83)\end{array}$ & $\begin{array}{l}2.5 \pm 3.5 \\
(0.3-8.7)\end{array}$ & $\begin{array}{l}2.12 \pm 0.85 \\
(1.36-3.31)\end{array}$ & $\begin{array}{c}2.96 \pm 4.03 \\
(0.37-10.10)\end{array}$ & $\begin{array}{l}7.31 \pm 2.37 \\
(4.33-9.19)\end{array}$ & $\begin{array}{l}1.90 \pm 1.60 \\
(0.40-4.00) \\
\end{array}$ \\
\hline $10(9)$ & $\begin{array}{l}2.73 \pm 0.39 \\
(1.84-3.14)\end{array}$ & $\begin{array}{l}1.9 \pm 0.6 \\
(0.8-2.6)\end{array}$ & $\begin{array}{l}3.19 \pm 0.45 \\
(2.14-3.66)\end{array}$ & $\begin{array}{l}2.25 \pm 0.75 \\
(0.88-3.03)\end{array}$ & $\begin{array}{c}9.94 \pm 2.59 \\
(4.74-12.90)\end{array}$ & $\begin{array}{l}3.38 \pm 0.32 \\
(2.90-4.00)\end{array}$ \\
\hline $7(6)$ & $\begin{array}{l}1.01 \pm 0.22 \\
(0.74-1.41)\end{array}$ & $\begin{array}{l}0.9 \pm 0.3 \\
(0.3-1.4)\end{array}$ & $\begin{array}{l}1.30 \pm 0.29 \\
(0.93-1.82)\end{array}$ & $\begin{array}{l}1.11 \pm 0.46 \\
(0.36-1.90)\end{array}$ & $\begin{array}{l}3.68 \pm 0.56 \\
(3.00-4.68)\end{array}$ & $\begin{array}{l}3.76 \pm 1.23 \\
(1.90-5.40)\end{array}$ \\
\hline
\end{tabular}

Data are presented as the mean, standard deviation and range for each of the seven individuals. The first individual listed was female, and the rest were males. 


\section{Supplementary Information}

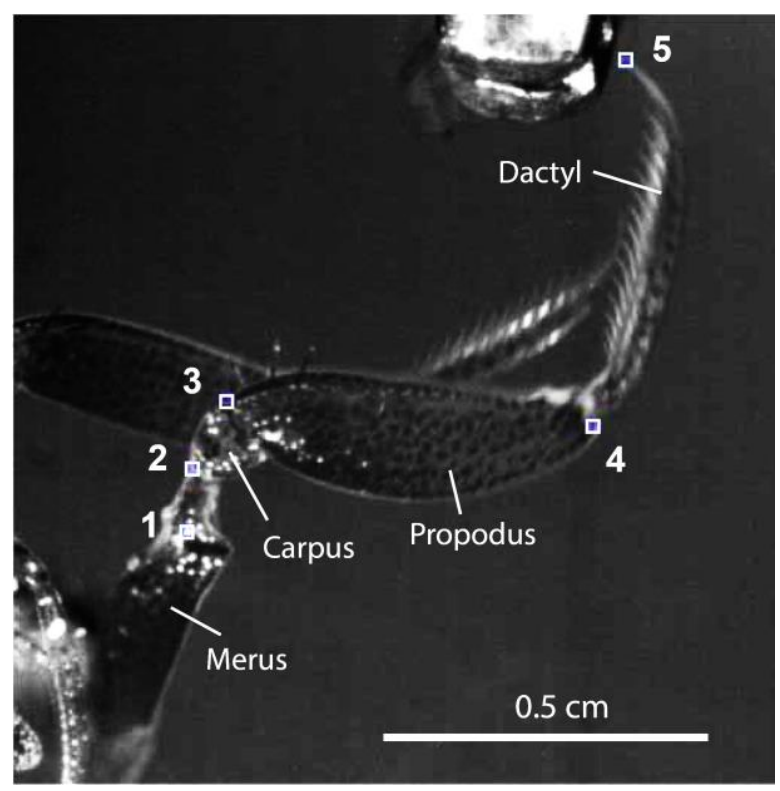

Supplementary Figure 1. Five points were tracked on each Coronis scolopendra individual's raptorial appendage during predatory strikes. The points correspond to: central merus (1), distal end of the merus (2), distal end of the carpus (3), distal end of the propodus (4), and distal end of the dactyl (5). This animal's raptorial appendage is shown in lateral view with distal toward the right of the page. 


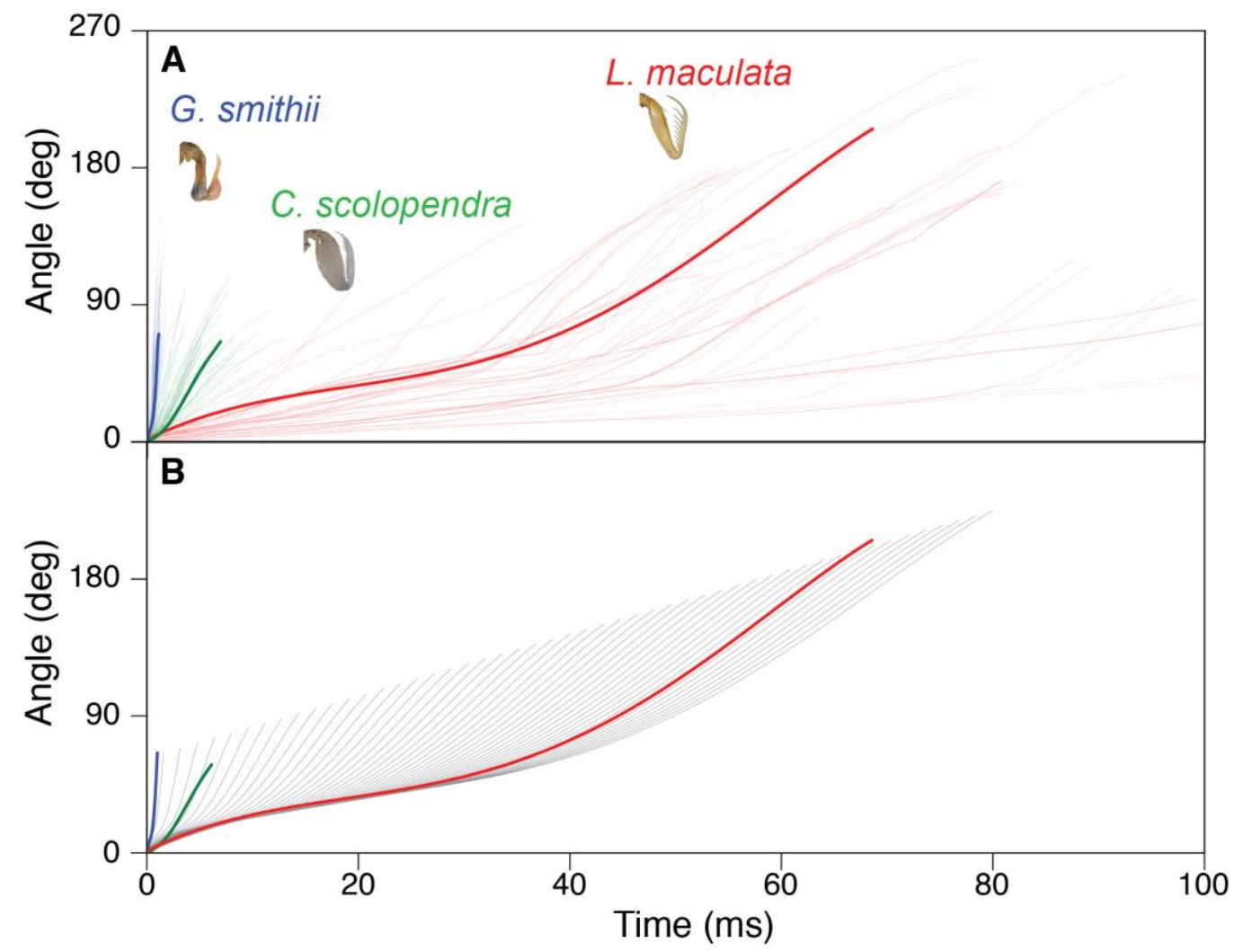

Supplementary Figure 2. Similar strike kinematics across mantis shrimp permitted generalized strike simulations. (A) Using kinematic data from previous studies and the present study, propodus rotations during raptorial strikes were plotted over time [red:

Lysiosquillina maculata (deVries, et al. 2012); green: Coronis scolopendra (this study); blue: Gonodactylus smithii (Cox, et al. 2014)] and the strike that was closest to the mean strike duration for the species was determined for each species (bolded lines). (B) We simulated the kinematics of all species with a fifth-order polynomial for the sigmoidal pattern of one particular strike from L. maculata. A sequence of strike simulations is shown (gray curves) that have scaled this strike to varying strike durations to illustrate how this simulated motion compares to the average strikes of each species (i.e., the same strike highlighted in A). 
A

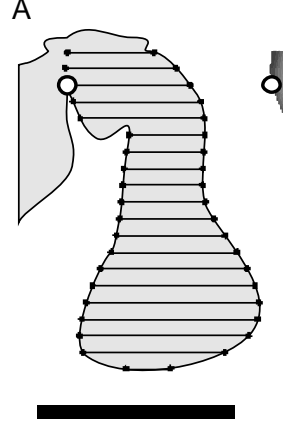

$\mathrm{B}$

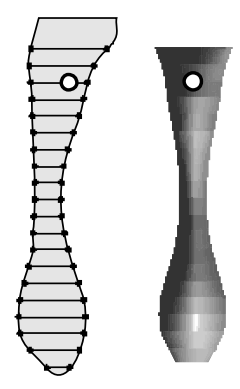

Supplementary Figure 3. Dimensions of the multi-frustum model fitted to the striking appendage of Gonodactylus smithii used in the computational fluid dynamics model.

The open circle indicates the center of rotation, and corresponds to the joint location between the carpus and merus (McHenry et al. 2012). The line drawings show the appendage contours (based on Figure 4 from McHenry et al. 2012) together with the axes of the twenty elliptical cylinders that served as base and top planes of the series of frustum segments (final 3D object views on the right). A. Lateral view images (distal to the toward right of page, dorsal toward the top of the page). B. Distal-proximal view images with lateral to the right, dorsal toward the top of the page. Note that the model assumes mirror symmetry about the sagittal plane through the long axis of the appendage. Scale bar, $5 \mathrm{~mm}$. 

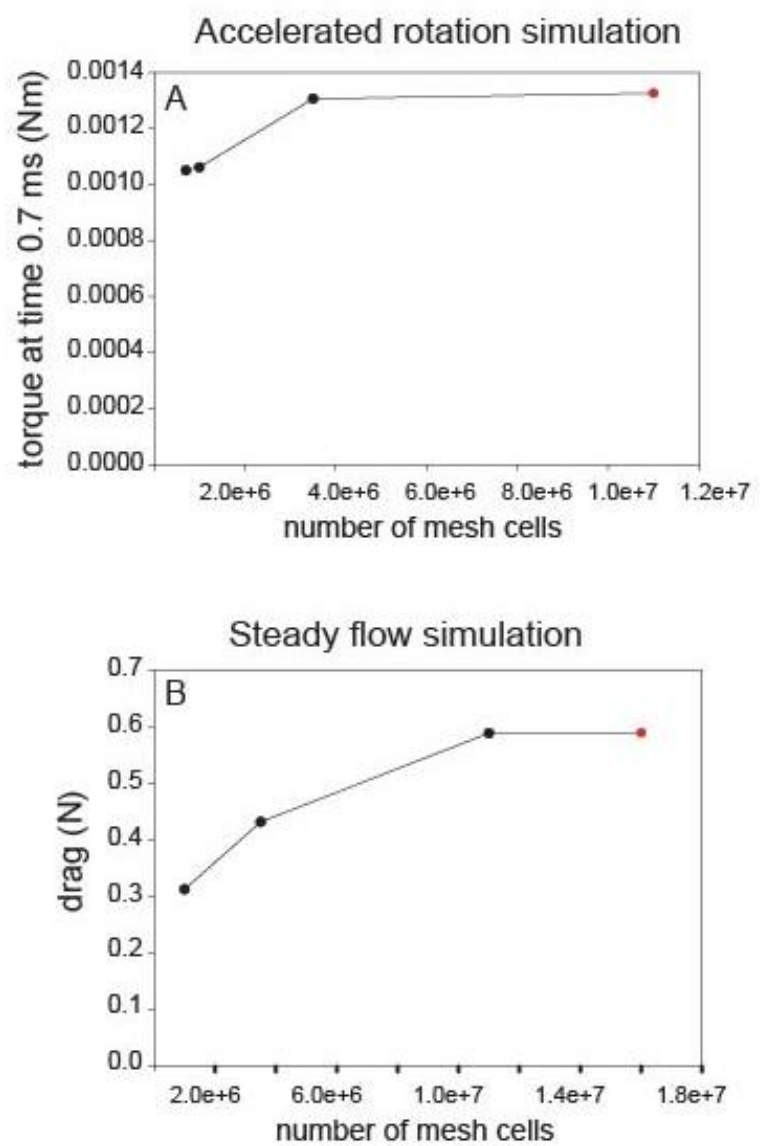

Supplementary Figure 4. Results from the mesh convergence analysis showing that the final mesh (red sphere) reached a converged solution for torque on the mantis shrimp model in the simulation of accelerated rotation (A) and for the steady flow simulation of linear flow over the model (B). 

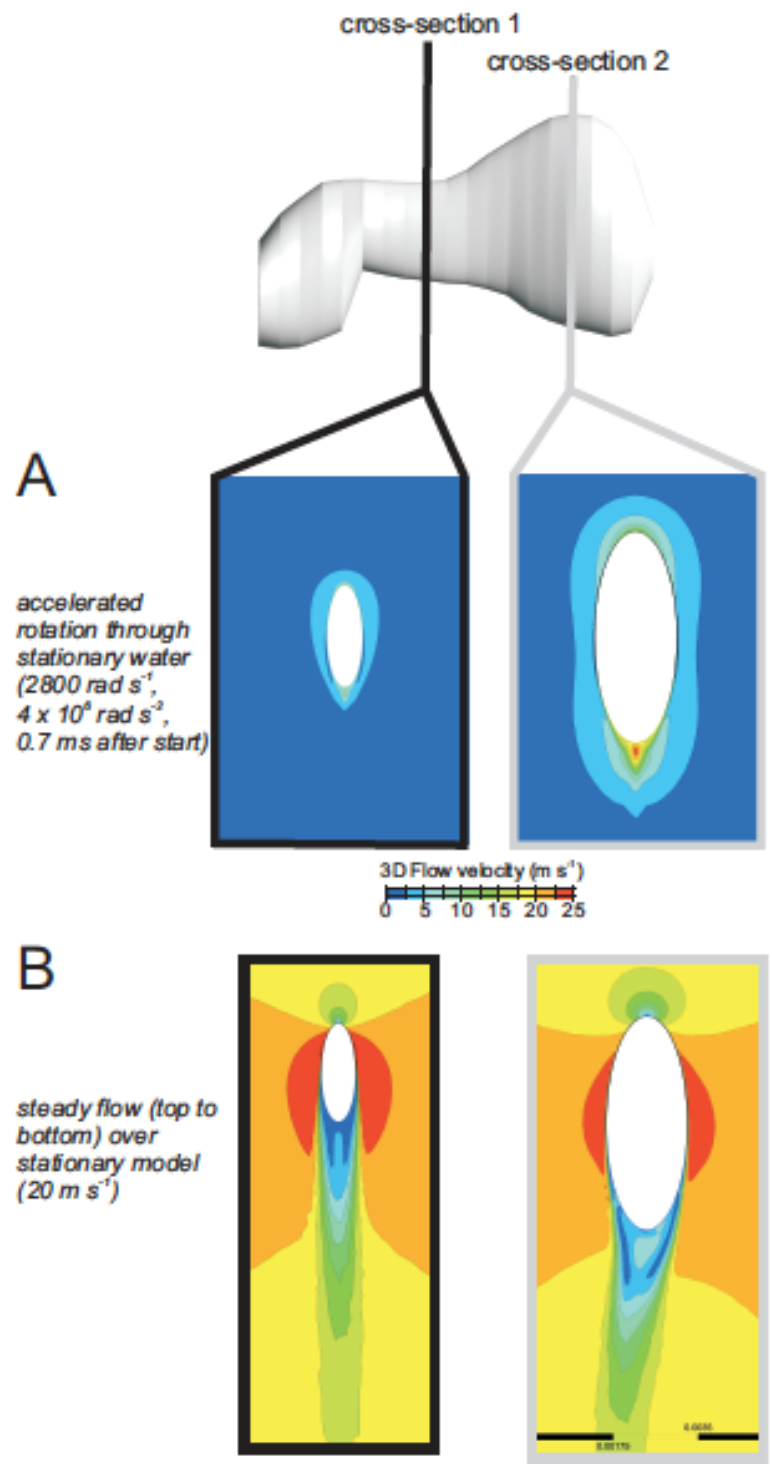

Supplementary Figure 5. Flow-patterns in the case of accelerated rotation of the mantis shrimp model (A), and for steady linear flow over the same model (B) as calculated by CFD. The results for 3D flow velocities are shown on two cross-sectional planes (position indicated in the top image). Note that the perspective differs between the two simulations: the model is moving through stationary water in (A), while the water is moved past the stationary model in (B). This figure shows that the flow pattern in the wake of a short acceleration from rest is notably different from the fully developed wake in a steady translation where twosided vorticity patterns are present. 
Supplementary Table 1. Scaling of physical models to achieve the same Reynolds number as calculated for the maximum speed and propodus length of each species (Table 1).

\begin{tabular}{c|c|c|c|c|c|} 
& $\begin{array}{c}\text { Maximum } \\
\text { speed } \\
(\mathbf{m} / \mathbf{s})\end{array}$ & $\begin{array}{c}\text { Propodus } \\
\text { length } \\
(\mathbf{m})\end{array}$ & $\begin{array}{c}\text { Scaled } \\
\text { appendage } \\
(\mathbf{m})\end{array}$ & $\begin{array}{c}\text { Scale } \\
\text { factor }\end{array}$ & $\begin{array}{c}\text { Reynolds } \\
\text { Number }\end{array}$ \\
\hline G. smithii & 30 & 0.005 & 0.15 & 30 & $1.4 \times 10^{5}$ \\
\hline G. falcatus & 30 & 0.005 & 0.15 & 30 & $1.4 \times 10^{5}$ \\
\hline $\begin{array}{c}\text { H. } \\
\text { californiensis }\end{array}$ & 3 & 0.027 & 0.24 & 9 & $7.7 \times 10^{4}$ \\
\hline $\begin{array}{c}\text { C. } \\
\text { scolopendra }\end{array}$ & 3.4 & 0.0085 & 0.23 & 30 & $2.7 \times 10^{4}$ \\
\hline L. maculata & 3 & 0.058 & 0.23 & 4 & $1.7 \times 10^{5}$ \\
\hline
\end{tabular}

The scale factors were used for setting the range of flume speeds (Table 3). Given that the maximum flow velocity of the flume is $1 \mathrm{~m} / \mathrm{s}$, the scale factor is equivalent to the maximum modeled speed for each scaled-up appendage. G. falcatus models were run at speeds based on published values for $G$. smithii (Cox, et al. 2014). H. californiensis models were run at speeds based on published values from L. maculata (deVries, et al. 2012). 
Supplementary Table 2: Drag (N) on each physical model tested

\begin{tabular}{|c|c|c|c|c|c|c|c|c|c|c|c|c|}
\hline \multicolumn{2}{|c|}{ Flume speed (m/s) } & 0.038 & 0.096 & 0.19 & 0.28 & 0.38 & 0.46 & 0.55 & 0.64 & 0.74 & $\mathbf{0 . 8 3}$ & 0.93 \\
\hline \multicolumn{13}{|c|}{ Drag $(\mathbf{N})$} \\
\hline \multirow{2}{*}{ G. smithii } & open & $<0.01$ & .02 & $0.0^{\prime}$ & 0.16 & .24 & 0.37 & 0.54 & 0.74 & 0.98 & 1.25 & 1.58 \\
\hline & clos & $<0.01$ & 0.01 & 0.04 & 0.09 & 0.13 & 0.20 & 0.30 & 0.41 & 0.55 & 0.69 & 0.93 \\
\hline \multirow{2}{*}{ G. falcatus } & open & $<0.01$ & 02 & 0.06 & 0.12 & 8 & 0.29 & 0.43 & 0.57 & 0.76 & 0.96 & 1.24 \\
\hline & $\operatorname{clos} \epsilon$ & $<0.01$ & $<0.01$ & 0.03 & 0.07 & 0.10 & 0.17 & 0.26 & 0.36 & 0.51 & 0.70 & 0.78 \\
\hline \multirow{2}{*}{$\begin{array}{l}H . \\
\text { californiensis }\end{array}$} & open & $<0.01$ & 0.03 & 0.12 & 0.24 & 0.38 & 0.56 & 0.83 & 1.12 & 1.63 & 2.04 & 2.63 \\
\hline & close & $<0.01$ & 0.03 & 0.09 & 0.18 & 0.30 & 0.47 & 0.69 & 0.94 & .19 & 1.45 & 1.86 \\
\hline \multirow{2}{*}{$\begin{array}{l}\text { C. } \\
\text { scolopendra }\end{array}$} & open & $<0.01$ & 0.02 & 0.06 & 0.14 & 0.21 & 0.33 & 0.47 & 0.63 & 0.84 & 1.06 & 1.33 \\
\hline & clos & $<0.01$ & 0.02 & 0.07 & 0.15 & 0.24 & 0.37 & 0.53 & 0.70 & 0.91 & 1.14 & 1.53 \\
\hline \multirow{2}{*}{ L. maculata } & open & $<0.01$ & 0.02 & 0.05 & 0.11 & 0.18 & 0.29 & 0.42 & 0.58 & 0.74 & 0.91 & 0.97 \\
\hline & closed & $<0.01$ & 0.02 & 0.05 & 0.11 & 0.17 & 0.26 & 0.39 & 0.51 & 0.65 & 0.82 & 1.02 \\
\hline
\end{tabular}

Each model was tested at a range of flume speeds with the dactyl in the open or closed position. Drag on each model configuration and flume speed is shown here. 
Supplementary Table 3. Hydrodynamic metrics of shape, determined from drag measurements

\begin{tabular}{|c|c|c|c|c|c|}
\hline \multirow[b]{2}{*}{ Species } & \multicolumn{2}{|c|}{$k$} & \multicolumn{3}{|c|}{$T_{\mathrm{d}}$} \\
\hline & $\begin{array}{l}\text { Dactyl } \\
\text { closed }\end{array}$ & $\begin{array}{l}\text { Dactyl } \\
\text { open }\end{array}$ & $\begin{array}{l}\text { Dactyl } \\
\text { closed }\end{array}$ & $\begin{array}{c}\text { Dactyl } \\
\text { open }\end{array}$ & Cylinder \\
\hline $\begin{array}{l}\text { G. smithii } \\
\text { (Smasher) }\end{array}$ & $1.06 \times 10^{-1}$ & $5.39 \times 10^{-2}$ & $3.79 \times 10^{-2}$ & $12.0 \times 10^{-2}$ & $8.40 \times 10^{-2}$ \\
\hline $\begin{array}{l}\text { G. falcatus } \\
\text { (Smasher) }\end{array}$ & $1.08 \times 10^{-1}$ & $5.13 \times 10^{-2}$ & $2.08 \times 10^{-2}$ & $3.38 \times 10^{-2}$ & $2.69 \times 10^{-2}$ \\
\hline $\begin{array}{l}\text { H. californiensis } \\
\text { (Undifferentiated) }\end{array}$ & $3.75 \times 10^{-2}$ & $3.08 \times 10^{-2}$ & $1.95 \times 10^{-2}$ & $5.00 \times 10^{-2}$ & $4.87 \times 10^{-2}$ \\
\hline $\begin{array}{l}\text { C. scolopendra } \\
\text { (Spearer) }\end{array}$ & $1.53 \times 10^{-2}$ & $3.95 \times 10^{-2}$ & $1.32 \times 10^{-2}$ & $1.77 \times 10^{-2}$ & $1.62 \times 10^{-2}$ \\
\hline $\begin{array}{l}\text { L. maculata } \\
\text { (Spearer) }\end{array}$ & $3.80 \times 10^{-2}$ & $5.82 \times 10^{-2}$ & $0.95 \times 10^{-2}$ & $0.96 \times 10^{-2}$ & $1.05 \times 10^{-2}$ \\
\hline
\end{tabular}

$k$, shape coefficient; $T_{\mathrm{d}}$, drag-torque index 